\title{
A Tale of Two States: Maharashtra and West Bengal $^{1}$
}

\author{
Amartya LahiRi AND KeI-MU Yi
}

October 2004

This Version: June 2005

\footnotetext{
${ }^{1}$ We would like to thank Satyajit Chatterjee, Hal Cole, Narayana Kocherlakota, as well as participants at the 2004 Iowa Development conference, 2005 Midwest Macro, Drexel, Iowa State, and Indian Statistical Institute Delhi for detailed comments and discussions. We thank Robin Burgess for providing the data in Besley and Burgess (2004). Thanks also to Edith Ostapik, Matthew Kondratowicz and Katya Vasilaky for excellent research assistance. The views expressed here do not necessarily reflect the views of the Federal Reserve Bank of New York, the Federal Reserve Bank of Philadelphia or the Federal Reserve System. Lahiri: International Research, Federal Reserve Bank of New York, 33 Liberty St., New York, NY 10045; amartya.lahiri@ny.frb.org. Yi: Research Department, Federal Reserve Bank of Philadelphia, 10 Independence Mall, Philadelphia, PA 19106; kei-mu.yi@phil.frb.org.
} 


\begin{abstract}
In this paper we study the economic evolution between 1960 and 1995 of two states in India - Maharashtra and West Bengal. During this period West Bengal, which was one of the two richest states in India in 1960, has gone from a relative per capita income of about 105 percent of Maharashtra to a relative income of around 69 percent. Our diagnostic analysis reveals that a large part of the blame for West Bengal's development woes can be attributed to: (a) low aggregate productivity (b) poorly functioning labor markets and sectoral misallocations. We find that sectoral productivity and labor market allocation wedges were strongly correlated with political developments in West Bengal, namely the increasing vote share of the leftist parties.
\end{abstract}

KEYWORDS: Indian states, development

JEL Classification: O11, O14 


\section{Introduction}

In 1960, two of the three richest states in India were Maharashtra and West Bengal. Maharashtra, home state of Mumbai (Bombay), and West Bengal, home state of Kolkata (Calcutta) were centers of commerce and industry. In addition, West Bengal had the social and

physical infrastructure that came with Calcutta's past as the long-standing capital of the British empire. Over the next three decades, however, the two states' economies diverged as West Bengal significantly under-performed relative to Maharashtra.

Drawing on data from multiple sources, we are able to quantify the extent of West Bengal's relative decline. According to our calculations, by 1993, its per capita output had fallen almost 35 percent relative to Maharashtra's. For a pair of regions at the top of the heap to diverge at a rate exceeding 1 percent a year for almost 35 years is remarkable in and of itself. What makes the experience of West Bengal and Maharashtra even more remarkable is that these two regions are located within the same country, and, as such, are subject to the same national policies.

The purpose of this paper is to better understand the relative decline of West Bengal and to shed light on the broad output and factor markets that may be the key sources of the decline. We believe this examination is a necessary first step to the ultimate goal of ascertaining the state-specific policies, institutions, and/or degree of implementation of national policies that may be the root causes of West Bengal's under-performance.

Our data analysis is mainly conducted from the prism of neoclassical growth theory. We first document the decline in West Bengal's per capita GDP relative to Maharashtra. We then turn to aggregate growth and (relative) levels accounting. Using data assembled from numerous sources, we find that West Bengal's under-performance can be attributed 
primarily to differences in TFP growth. These differences accounted for about 60 percent of the differential performance of West Bengal's per worker GDP relative to Maharashtra's per worker GDP between 1961 and 1991. Human and physical capital account for the remainder, with human capital playing a slightly larger role.

We then examine relative sectoral performance. We find that the manufacturing sector share of West Bengal's output dropped sharply during this period from 22 percent to 15 percent, while Maharashtra's manufacturing share increased. The flip side of this differential performance in manufacturing was agriculture. While the agricultural share of total GDP declined in both states, West Bengal's fell far less than Maharashtra's. ${ }^{1}$

To pursue the sources of the decline further, we conduct a model-based diagnostic exercise that identifies the margins that may have been responsible for the performance disparity. Specifically, we employ a methodology recently developed by Cole and Ohanian; Chari, Kehoe, and McGrattan; and Mulligan. This methodology involves creating the empirical counterparts to the firm and household first order conditions from a neoclassical growth model. If efficiency or optimality holds, then the ratio of the left-hand side to the right-hand side of a first order condition should be one. To the extent this ratio does not equal one, a "wedge" exists, possibly caused by policy distortions. A key feature of our diagnostic framework is that it has three sectors, agriculture, manufacturing, and services. This allows us to account for the differential sectoral performance of the two states that we documented.

For the manufacturing sector, we find that about 35 percent of the differential output performance is due to labor market inefficiencies or wedges. The labor market wedges indicate that the marginal product of labor in West Bengal's manufacturing sector was too low relative

\footnotetext{
${ }^{1}$ The share of total GDP of the other key sector, services, increased in both states. Agriculture, manufacturing and services comprise about 90 percent of output of these two states during this period.
} 
to labor's marginal product in the services sector. The remaining 65 percent difference is attributed to differences in sectoral productivity. In the services sector on the other hand, almost the entire relative output decline in West Bengal is attributable to sectoral productivity. Interestingly, we find that agricultural productivity in West Bengal relative to Maharashtra remained unchanged between 1960 and 1995. However, there was an increase in the relative agricultural share of the labor force in West Bengal during this period. This positive agricultural employment effect was the primary reason for the relatively muted decline in agricultural's share of output in West Bengal.

Guided by the diagnostic results, we investigate one proximate explanation for the difference in the relative performance of West Bengal. We find that the incidence of industrial action in West Bengal (measured by the ratios of days lost to days worked) increased sharply in the mid-1960s and thereafter has remained at about three times the level in Maharashtra. Moreover, we find that the incidence of industrial action is positively correlated with political developments in West Bengal, namely the increasing vote share of the leftist parties over the last 35 years. The vote share of the leftist parties, in turn, is positively correlated with our measured wedges. This suggests to us that an increase in the bargaining power of labor in West Bengal may have been a significant ingredient in the relative decline of West Bengal.

We find the results interesting on two counts. First, as alluded to above, we are unable to find a similar example of two regions within the same country, who were jointly at the top of the income distribution at some point in time, exhibiting such a marked difference in economic performance over a 35 year period. Indeed, even looking at the cross-country income data it is hard to find similar cases. As pointed out by Kehoe and Ruhl (2003), there are a couple of cases like New Zealand and Switzerland which showed 40 percent declines in per capita incomes relative to the USA between 1960 and 2000. However, New Zealand 
(4 million people in 2000) and Switzerland (7 million) are tiny when compared with West Bengal (80 million) and Maharashtra (97 million). Second, the correlation of the measured wedges in sectoral labor allocation conditions and sectoral productivity with the vote share of the leftist parties point to promising avenues for quantifying the effects of aggressive pro-labor industrial work rules as well as state sanctioned industrial action.

Our paper is related to Besley and Burgess (2004) [4]. [4] use similar data to study the evolution of the manufacturing sector across Indian states. Based on a detailed study of amendments to labor regulations in different states, [4] construct an index which classifies each state as being either pro-labor, neutral or pro-employer. They find that pro-worker legislation reduced growth of manufacturing output, investment and employment. Moreover, pro-labor regulation also slowed down the rate of poverty reduction. While our results are consistent with the findings of [4], we should note that their index classifies both West Bengal and Maharashtra as being pro-labor. Hence, their index is not directly informative about the different development patterns of these two states. ${ }^{2}$

In the next section we describe the data and document some of the broad stylized facts between the two states. We also employ a growth and levels accounting framework to calculate the broad sources of growth in each state, as well as the sources of differences in per capita income. In section 3, we use a standard neoclassical growth model to conduct some diagnostic tests on the data. Section 4 evaluates some potential explanations for the diagnostic results, and section 5 concludes.

\footnotetext{
${ }^{2}$ As further support for our diagnosis of the labor market being the problem in West Bengal, [4] report that "West Bengal was also a state which had the greatest body of pro-labor regulation passed in state legislature."
} 


\section{Key Stylized Facts}

In this section we present several key stylized facts. We first illustrate the magnitude of the decline in West Bengal's per capita net state domestic product (NDP) relative to that of Maharashtra. Then, we perform a relative levels and growth accounting decomposition. Lastly, we examine the role of different sectors - agriculture, manufacturing, and services, in the decline.

Our data draws from many sources. Our primary source for state domestic product and physical capital data is the detailed India data set put together by the Economic and Political Weekly Research Foundation (EPW). In addition, we employ price data from the World Bank data set on India assembled by Ozler, Datt, and Ravallion (1996). We draw our population and schooling data from the India Census (1961, 1971, 1981, and 1991). Lastly, we employ the Annual Survey of Industries (ASI), as well as some of the data from Besley and Burgess (2004), to obtain detailed state-level manufacturing sector data. The Data Appendix provides more details on our sources as well as on how we construct our variables, but the most salient issues are discussed here.

In order to compare per capita incomes across states, we splice several constant-price net state domestic product (NDP) series covering 1960 through 1993. The series are normalized to 1993 prices. The resulting series are still not comparable across states, because aggregate prices may differ across states. To make state-level comparisons possible, we employ two consumer price indices from the World Bank data set, one for industrial workers and one for agricultural laborers, which are adjusted for inter-state price differences, i.e., they are all expressed relative to an all-India price index. For each state, we take an average of these two indices in 1993 and then divide this average by Maharashtra's average. We multiply this 
Figure 1: Real per capita income relative to Maharashtra; Major Indian states, 1960 and 1993

Per capita Real* State Domestic Product Relative to Maharastra

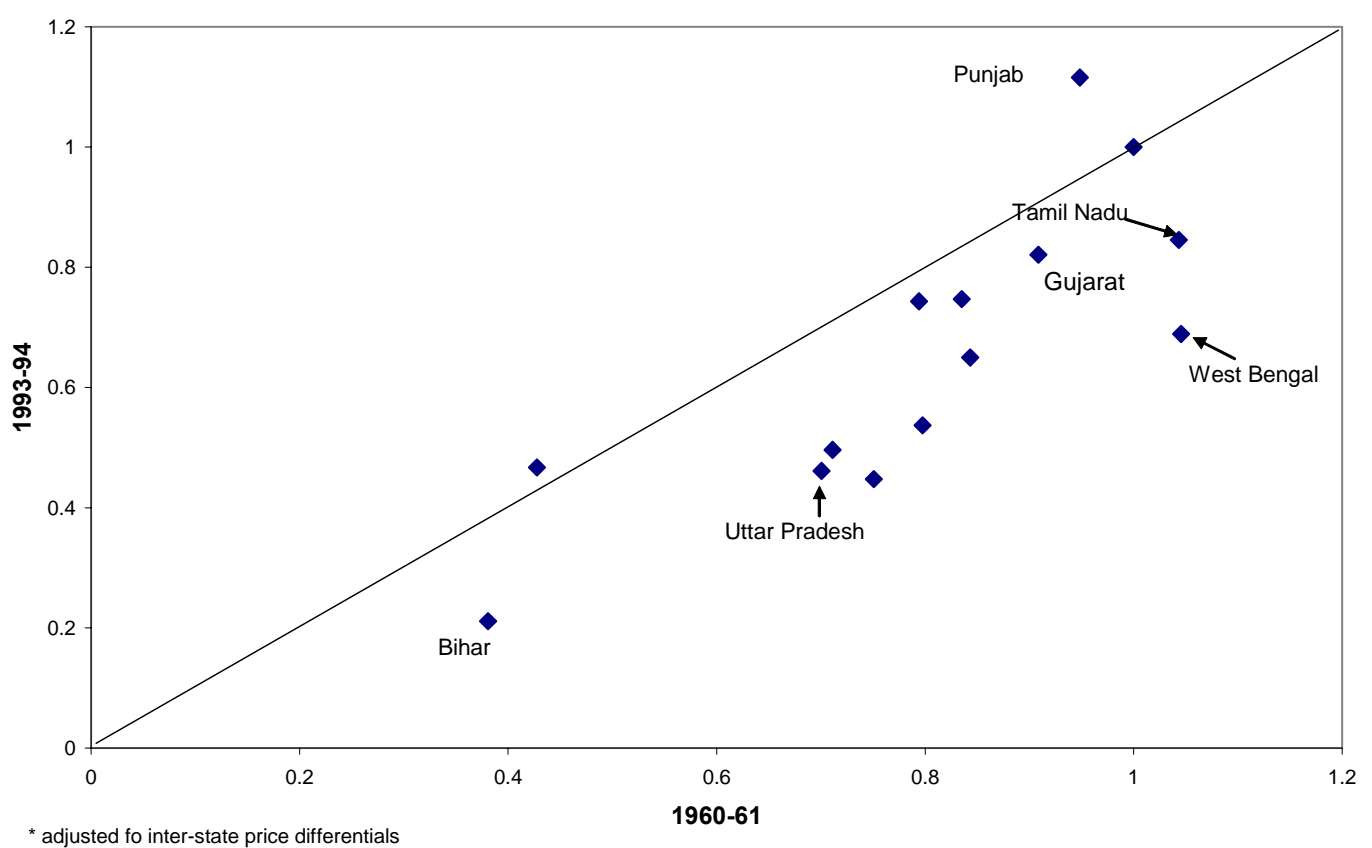

ratio by the constant-price NDP series. Lastly, we divide by population for each year, where population in years between Census years (1961, 1971, 1981, and 1991) are interpolated.

Figure 1 shows the state-level distribution of per capita NDP in 1960 and 1993, expressed relative to Maharashtra. Maharashtra was the third richest state in 1960, while West Bengal was the richest state in India with a per capita income that was about 5 percent higher than Maharashtra's. However, by 1993, West Bengal's per capita income had fallen to just 69 percent of Maharashtra's. Meanwhile Maharashtra became the second richest state. In addition, the fall in West Bengal's relative income was the largest drop in percentage point terms across all the states.

In Figure 2 we plot the time series evolution of the per capita state domestic product 
Figure 2: Per capita NDP: Maharashtra, West Bengal, Rest of India, 1993-94 prices

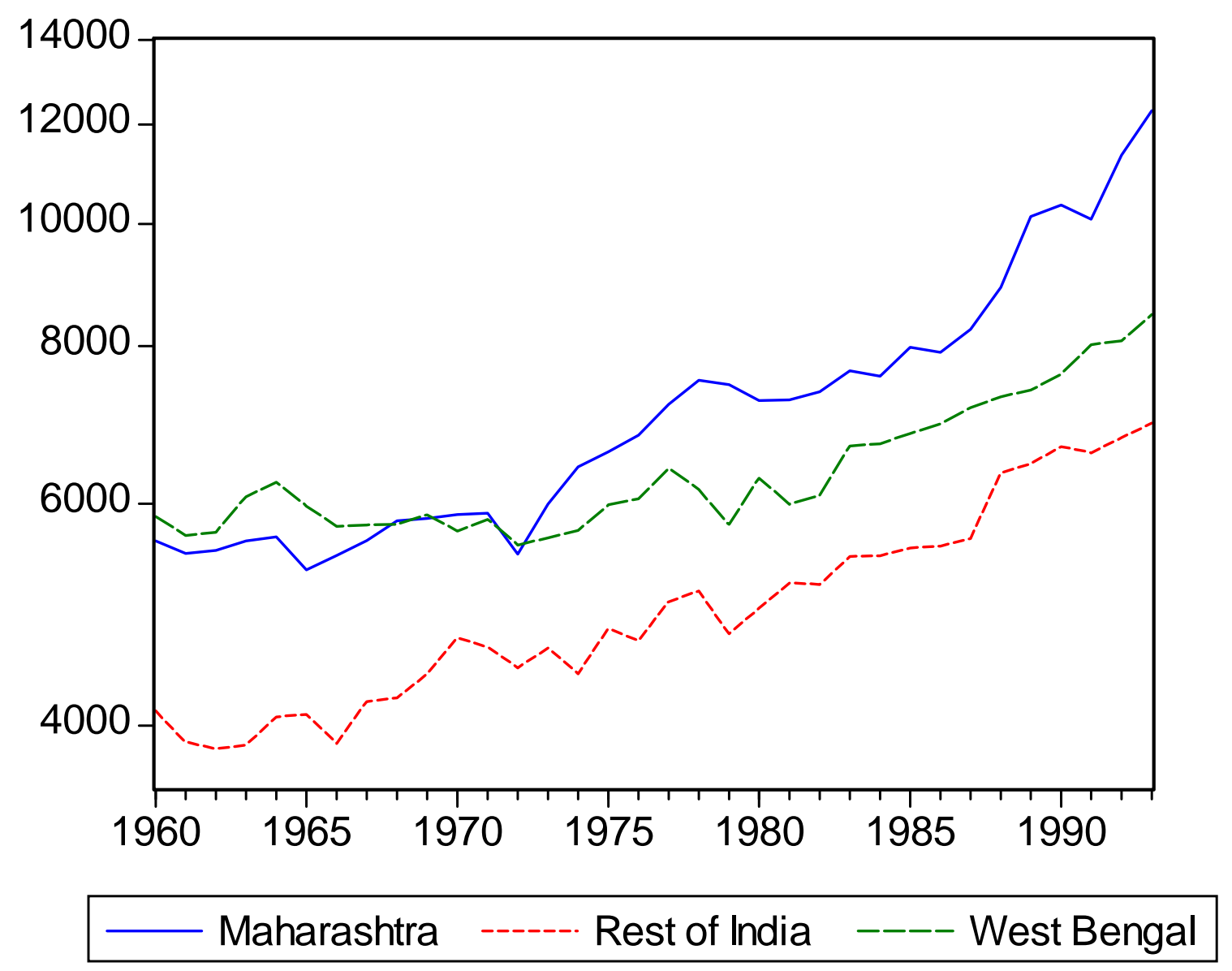

(SDP) of Maharashtra, West Bengal, and the rest of India. The figure suggests that the decline in the relative per capita income of West Bengal has been going on for decades, and that even as West Bengal is losing ground to Maharashtra, the rest of India is catching up to West Bengal. ${ }^{3}$

A fall in income of this magnitude in such a short period of time by a leading economy is ${ }^{3}$ It is worth pointing out that population in West Bengal and Maharashtra have followed very similar
paths. West Bengal's population has been between 86 and 88 percent of Maharashtra's between 1961 and
1993. So differences in per capita NDP performance cannot be attributed to unusual population dynamics. 
rare. To put this in perspective, consider the OECD countries' performance relative to the United States between 1960 and 2000. Kehoe and Ruhl (2002) use the Penn World Tables data to show that the two countries that suffered sharp drops in their per capita income relative to that of the United States were New Zealand and Switzerland. Both declined by about 40 percent relative to the United States. However, the population of New Zealand and Switzerland in 2000 are 3.9 million and 7.2 million, respectively. By contrast, the population of West Bengal in 1991 (2001) was 68 million (80 million). The relative decline of a region that is 20 times as populous as New Zealand and 10 times as populous as Switzerland, and, moreover, is within the national boundaries as the faster growing regions, is what makes this case study so compelling.

We now turn to growth accounting in order to establish the relative importance of three broad sources of per worker growth, total factor productivity, physical capital, and human capital, in each state. ${ }^{4}$ We also perform relative levels accounting - we examine the sources of differences between West Bengal's per worker output and Maharashtra's per worker output relative to their differences in 1961. Our approach follows that of Hall and Jones (1999). This approach begins with the usual human capital augmented form of the production function:

$$
Y_{i}=K_{i}^{\alpha}\left(H_{i} A_{i}\right)^{1-\alpha}
$$

where $Y$ is output, $K$ is capital, $A$ is total factor productivity (TFP), and $H$ is human capital. Hall and Jones (HJ) employ $H=e^{\phi(E)} L$, where $L$ is labor. $\phi(E)$ "reflects the efficiency of a unit of labor with $E$ years of schooling relative to one with no schooling" (HJ,

\footnotetext{
${ }^{4}$ We perform per worker accounting, as opposed to per capita accounting, to be consistent with Hall and Jones (1999). Doing per capita accounting would add an additional variable, the employment share of the population. But, it would not affect the importance of total factor productivity relative to human capital and physical capital in the accounting.
} 
p. 87). $\phi^{\prime}(E)$ is the Mincerian return to schooling. The production function can be rewritten in per worker terms as follows:

$$
y_{i}=\left(\frac{K_{i}}{Y_{i}}\right)^{\frac{\alpha}{1-\alpha}} h_{i} A_{i}
$$

where lower case letters denote the variable expressed in per worker form. Compared to the usual per worker production function, this representation attributes changes in capital that are endogenous responses to changes in total factor productivity (TFP) $A_{i}$, to TFP. We use the above for our levels accounting. For our growth accounting, we take logarithmic derivatives of $(2)$ :

$$
\widehat{y}=\frac{\alpha}{1-\alpha} \widehat{\left(\frac{K}{Y}\right)}+\widehat{h}+\widehat{A}
$$

We employ data on net state domestic product, physical capital, schooling, and workers to construct our variables and perform our calculations. The labor and schooling data come primarily from the Census of India; consequently, we focus on the four census years 1961, 1971, 1981, and 1991. The net domestic product come from the EPW. We use the spliced constant price NDP data discussed above. However, we do not employ the price adjustment that facilitates comparability at a point in time, because our interest in this section is on growth and relative levels accounting. There is no physical capital stock data available at the state level, but we impute these data using state and sector-level current price NDP data in conjunction with all-India constant-price sector-level capital stock data. ${ }^{5}$ The imputation assumes that production technologies have the same functional form across states and that prices of capital are equalized across states. Details on the data sources, how the physical

\footnotetext{
${ }^{5}$ The ASI contains physical capital stock data at the state level for the manufacturing sector. But, there is no analogous data for other sectors.
} 
Figure 3: Human Capital: West Bengal, Maharashtra, India

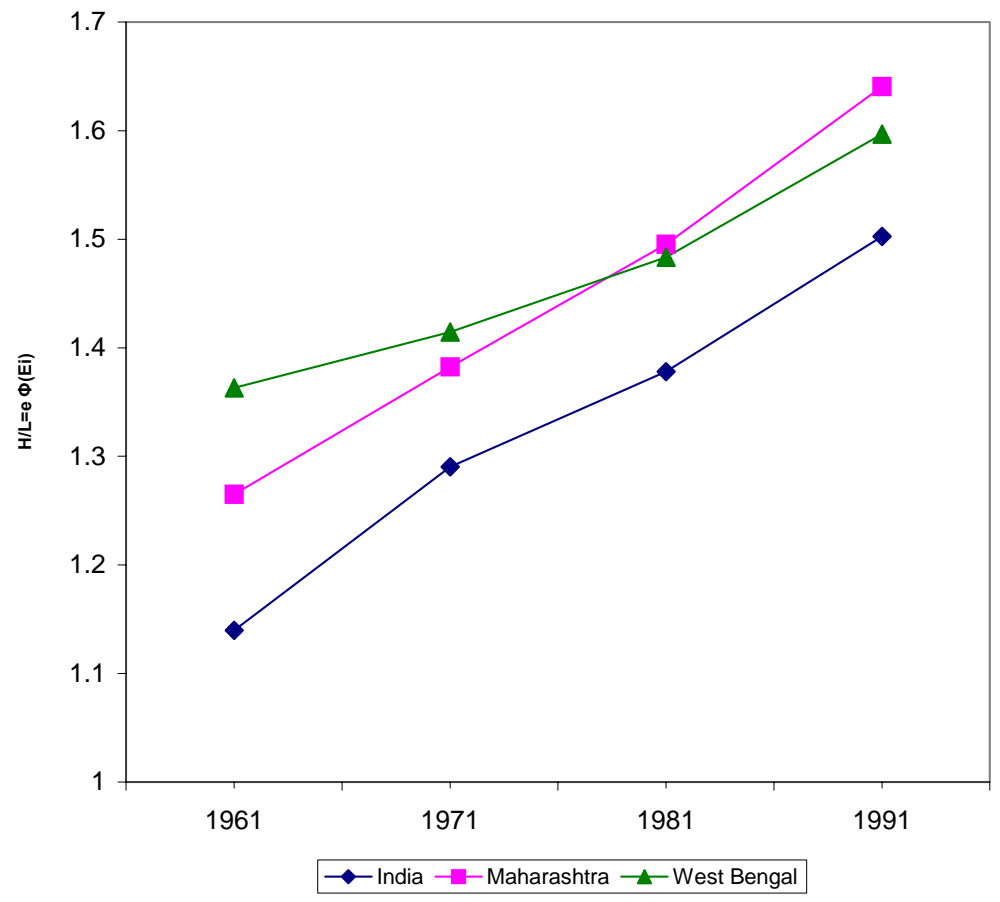

and human capital variables are constructed, and on issues with the labor data are provided in the Data Appendix.

The key parameters are the capital share of output and the exact functional form for $\phi(E)$. In both cases we follow HJ. Specifically, the capital share we employ is $1 / 3$; this is close to the "naive" measure that Gollin (2002) calculates for India. HJ rely on Psacharopoulos (1994) who calculates the returns to schooling as a piecewise linear functional form. The exact returns are presented in Appendix I. Figure 3 illustrates human capital for West Bengal, Maharashtra, and India. It shows that Maharashtra's human capital surpassed West Bengal's during the 1970s. In 1961, human capital in West Bengal was 8 percent higher than in Maharashtra, but by 1991, it was 3 percent lower than in Maharashtra. 
Table 1 lists values for per worker output, capital/output ratio (raised to the $1 / 2$ power), human capital, and TFP for each state for each of the four census years. We first focus on the sources of growth between 1961 and 1991. Per worker output in Maharashtra grew 125 percent between 1961 and 1991, almost three times as much as West Bengal's growth. In Maharashtra, (log) growth in total factor productivity (TFP) accounts for almost half of Maharashtra's per worker output growth. (Log) human capital and physical capital growth account for 32 and 21 percent of Maharashtra's growth, respectively. In West Bengal, by contrast, (log) growth in TFP accounts for only 30 percent of West Bengal's per worker output growth, with human capital and physical capital accounting for 44 and 26 percent of West Bengal's growth, respectively.

Table 2 examines the sources of differences between West Bengal to Maharashtra. Mindful that the per worker output numbers are not directly comparable, we normalize the West Bengal to Maharashtra ratio to be 1 in 1961 . The table shows that per worker output in West Bengal relative to Maharashtra in 1991 was only 63.7 percent of its value in 1961. This is consistent with the per capita evidence presented earlier. The table shows that West Bengal's relative (to Maharashtra) physical capital, human capital, and TFP were all lower in 1991 than in 1961. The gap in TFP is the largest, and accounts for 60 percent of the overall gap (in log terms). Human and physical capital account for 23 and 18 percent of the gap, respectively. Thus, TFP was the primary force, but differences in human and physical capital were significant, as well.

We engage in several robustness exercises, involving a different $\phi(E)$ function that draws from estimates on India data, as well as three adjustments to employment. ${ }^{6}$ In all these

\footnotetext{
${ }^{6}$ Our alternative set of returns for $\phi(E)$ come from Duraisamy (2002), who estimates them on Indian data from 1983-94. The adjustments to employment are to improve consistency of the employment data across
} 
exercises, the overall pattern remains the same: Differences in TFP growth account for the majority of the difference in per worker output growth rates.

Lastly, we examine the sectoral performance of the two states. In particular, we are interested in determining whether the poor performance of West Bengal can be accounted for primarily by poor performance in a particular sector or by poor performance in all sectors. Accordingly, in figure 4 we present the agriculture, manufacturing, and services share of (current price) NDP for the two states in 1960 through 1995. The figure reveals that agriculture's share of output declined in both states, but the decline was much more pronounced in Maharashtra. A second major difference is in the evolution of the manufacturing sector. In Maharashtra manufacturing increased its share of output between 1960 and 1995, while in West Bengal the manufacturing share of output decline from 20 percent to 15 percent in that period. Manufacturing in West Bengal experienced a de-industrialization. The share of services in output increased similarly in both states.

The striking difference in manufacturing performance leads us to do undertake a further analysis of the sector in the two states. We do this by analyzing survey data on the registered manufacturing sector drawn from the ASI and Besley and Burgess (2004). The advantage of the survey data on registered manufacturing is that it contains detailed data on capital and employment. Registered manufacturing comprises, on average, 80 percent of the manufacturing sectors in West Bengal and Maharashtra.

Figures 5-7 show the evolution of manufacturing output as well as manufacturing output per unit labor, capital, and employment in West Bengal relative to Maharashtra over the period 1960-95.

The message of these figures is that starting from an initial position of roughly equal size Census years. Further details are discussed in the Data Appendix. 
Figure 4: Sectoral share of output
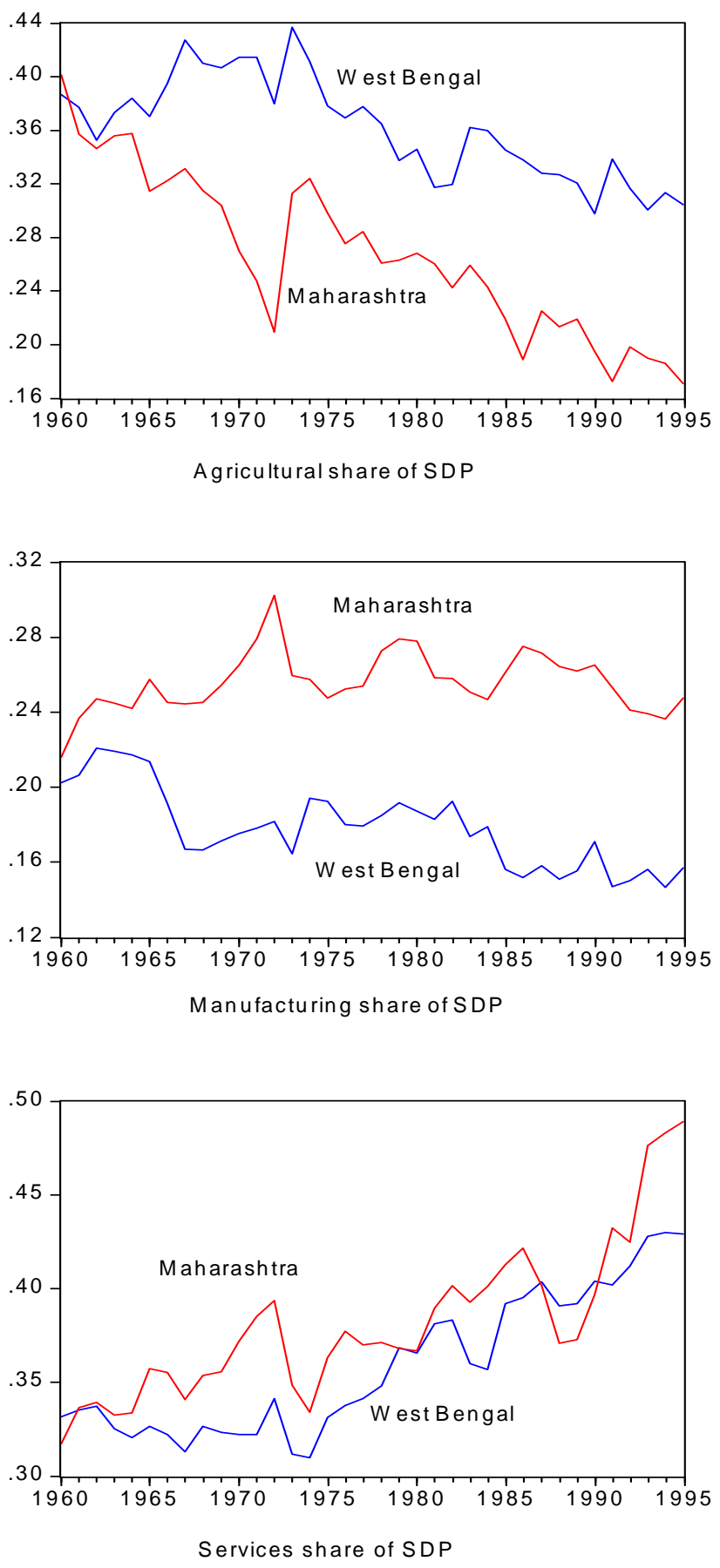
Figure 5: Relative registered manufacturing output

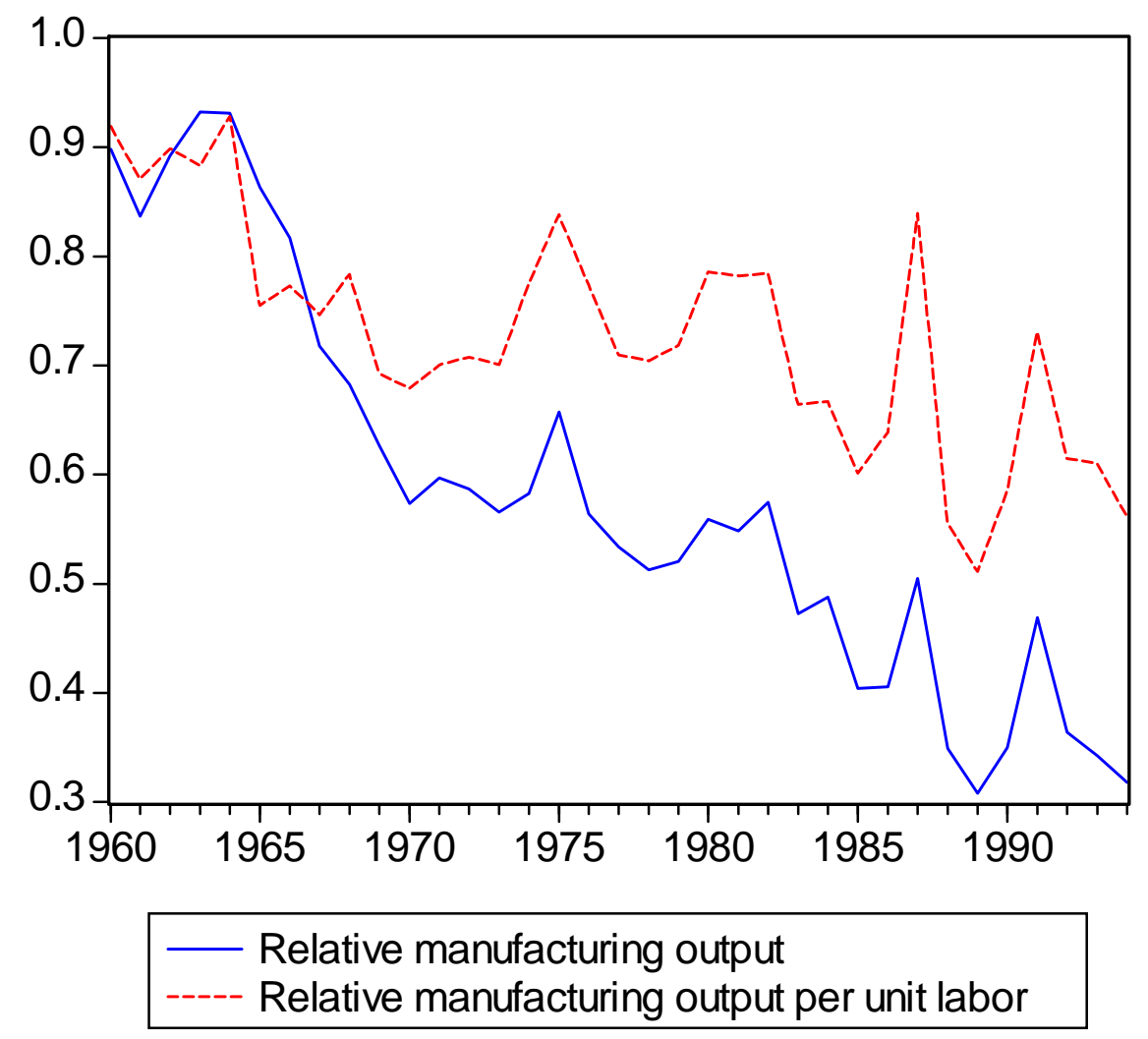


Figure 6: Relative manufacturing capital

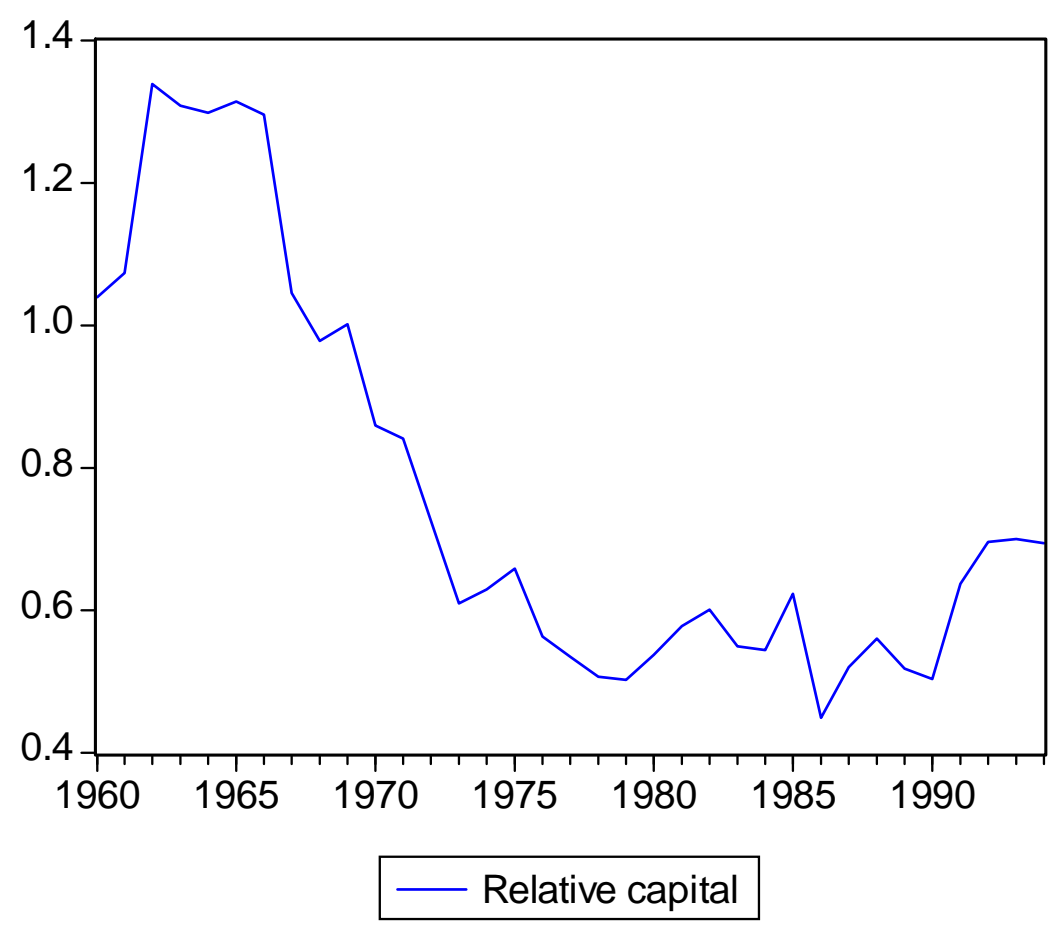

in manufacturing with Maharashtra, there was a secular decline in output, labor productivity, and inputs in West Bengal during the next 35 years. For capital (as well as investment), West Bengal was ahead of Maharashtra in 1960, but subsequently declined to about 40 percent of Maharashtra by 1995.

To summarize, in this section we document that West Bengal's per capita income fell by about 35 percent relative to Maharashtra's (or put differently, Maharashtra gained about 50 percent relative to West Bengal). We also show that TFP accounts for the majority of the relatively poor performance of West Bengal's per worker income between 1961 and 1991. Physical and human capital play significant roles, as well, although the two capital stocks, taken together, account for only 40 percent of the gap (in log terms) in performance during this period. Lastly, we show that a key sector accounting for this decline was manufacturing, 
Figure 7: Relative manufacturing employment

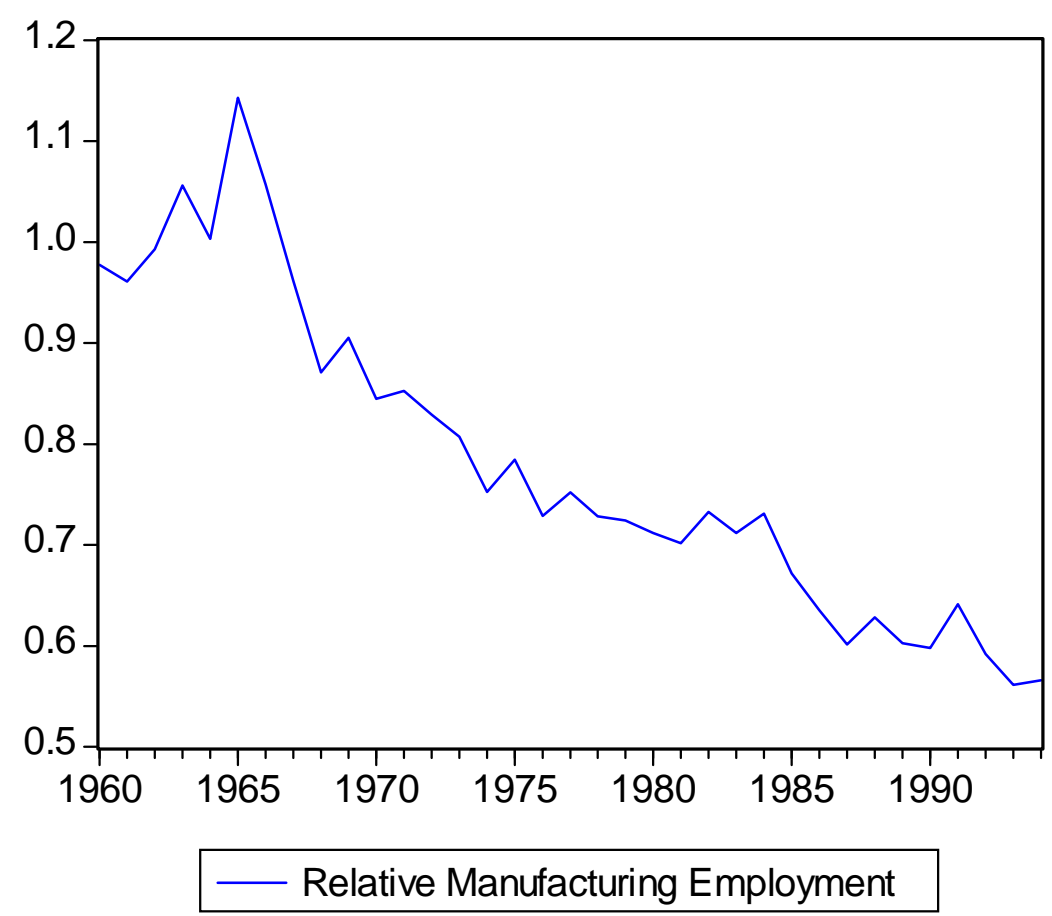

which experienced a secular decline in both productivity and inputs relative to Maharashtra during this period. ${ }^{7}$

\section{$3 \quad$ Model-based Diagnostics}

The previous section showed that TFP and the manufacturing sector have played major roles in the relative decline in West Bengal. We now turn to a model-based diagnostic exercise to learn more about the forces that contributed significantly to West Bengal's decline. Our framework draws from the methodology developed by Cole and Ohanian (2002, 2004),

\footnotetext{
${ }^{7}$ We examined the sectoral composition of manufacturing, comparing 1979 to 1995. In West Bengal the composition remained relatively unchanged, suggesting that a large shock to one particular manufacturing sector did not drive the overall manufacturing performance.
} 
Chari, Kehoe and McGrattan (2004), and Mulligan (2002). ${ }^{8}$ The methodology begins with an economic model, typically the neoclassical growth model. The main diagnostic device consists of computing the "wedges" in the first order conditions of the model and determining the conditions that deviate the most from optimality. The deviations provide guidance on which sectors or features of the economy deserve special attention by model-builders.

We modify the methodology by employing a multi-sector version of the neoclassical model. This reflects the fact that our review of the key stylized facts suggests that differences in sectoral performance over time may be crucial in understanding the overall performance differential between West Bengal and Maharashtra.

Consider an economy (country) composed of a number of constituent states. Each state has four sectors of production - a final good sector, and three intermediate goods sectors: agriculture, manufacturing and services. Each state is assumed to be small and takes as exogenous the prices of goods that are tradable across states within the country. The manufacturing and agricultural goods are assumed to be freely tradeable while the services and final goods are non-tradable. The agriculture, manufacturing and services goods are inputs into a production technology which produces a non-traded final good that can be consumed or invested.

The representative household in each state maximizes the present discounted value of lifetime utility with instantaneous utility being given by

$$
u(c, l)=\log c+\psi \log (\bar{l}-l)
$$

where $c$ is consumption per person, $l$ is labor supply (hours worked), and $\bar{l}$ is the total endowment of labor hours available to the agent. The optimization is done subject to the

\footnotetext{
${ }^{8}$ This methodology is related to work by Ingram, Kocherlakota, and Savin (1994) and by others.
} 
budget constraint:

$$
c_{t}+k_{t+1}=w_{a t} l_{a t}+w_{m t} l_{m t}+w_{s t} l_{s t}+\left(r_{t}+1-\delta\right) k_{t}+\Pi_{t}+\Pi_{t}^{a}+\Pi_{t}^{m}+\Pi_{t}^{s}+T_{t}
$$

where $k$ is the capital stock per person, $\delta$ is the depreciation rate while $w_{i}$ is the wage rate in sector $i(i=a, m, s) . \quad r$ is the interest rate while $\Pi, \Pi^{a}, \Pi^{m}$, and $\Pi^{s}$ are dividends from final goods, agriculture, manufacturing, and service sector firms. $T=p_{a} T_{a}+p_{m} T_{m}$ denotes unilateral transfers of the tradable agricultural and manufacturing goods from the rest of the world. Note that we are using the final good as the numeraire good so that all prices are expressed in units of the final good. In addition to the budget constraint, households also face the time endowment constraint: $l_{m}+l_{a}+l_{a}=l$. The representative household's problem leads to first-order conditions (3) and (4):

$$
\begin{aligned}
\chi \frac{c_{t}}{\bar{l}-l_{t}} & =w_{t} \\
\frac{1}{c_{t}} & =\beta\left[\frac{r_{t+1}+1-\delta}{c_{t+1}}\right] \\
w_{a t} & =w_{m t}=w_{s t}=w_{t}
\end{aligned}
$$

These are standard optimality conditions with equation (3) determining the optimal consumptionleisure choice while (4) is the intertemporal Euler equation determining savings. Equation (5) shows that wages must be equalized across sectors, because labor reallocation across sectors is assumed to be costless.

We assume that the production technologies in the four sectors of the economy are given 
by

$$
\begin{aligned}
& y_{m}=k^{\alpha}\left(x_{m} l_{m}\right)^{1-\alpha} \\
& y_{a}=\left(x_{a} l_{a}\right)^{\mu} \\
& y_{s}=\left(x_{s} l_{s}\right)^{\sigma} \\
& y=\hat{y}_{s}^{\theta} \hat{y}_{m}^{\gamma} \hat{y}_{a}^{1-\gamma-\theta}
\end{aligned}
$$

where $y_{j}$ is total output of good $j=a, m, s$ while $y$ is the output of the final good. $\hat{y}_{j}$ denotes the use of good $j=a, m, s$ in producing the final good. Note that usage of goods $a$ and $m$ in any state need not equal output of the goods in a state, because these intermediates can be traded. $x_{j}(j=a, m, s)$ is the level of the labor augmenting technology factor. We are assuming here that the agriculture and service sectors are Ricardian in that they only use labor to produce, while the manufacturing sector uses both labor and capital.

At this point, we should note that several of our modeling assumptions are driven by lack of data. For example, our assumption that agriculture and services are produced only from labor reflects a major data limitation in that we do not have direct measures of capital use for any sector other than manufacturing. ${ }^{9}$ In addition, while there is obviously trade across states, we do not have this data. However, we do have data on the relative price of agriculture to industry (which we use as our proxy for $p_{a} / p_{m}$ ); in conjunction with the fact that commodities tend to be more traded than services, we assumed agriculture and manufacturing are traded, while services are non-traded. Lastly, the lack of sector-level consumption data led us to adopt the assumption of an Armington aggregator, in which the uses of sectoral outputs are combined to produce a single non-traded final good used for

\footnotetext{
${ }^{9}$ Also, we do not have state level time series data on savings or investment. Our investment data is only for the manufacturing sector.
} 
consumption and capital accumulation.

Perfectly competitive firms in each sector maximize profits which are given by:

$$
\begin{aligned}
& \Pi_{t}=y_{t}-p_{m t} \hat{y}_{m t}-p_{a t} \hat{y}_{a t}-p_{s t} \hat{y}_{s t} \\
& \Pi_{t}^{m}=p_{m t} y_{m t}-w_{m t} l_{m t}-r_{t} k_{t} \\
& \Pi_{t}^{a}=p_{a t} y_{a t}-w_{a t} l_{a t} \\
& \Pi_{t}^{s}=p_{s t} y_{s t}-w_{s t} l_{s t}
\end{aligned}
$$

Final goods firms choose $\hat{y}_{m t}, \hat{y}_{a t}$ and $\hat{y}_{s t}$ to maximize $\Pi$ subject to the production technology for producing $y$. The first order conditions for optimal $\hat{y}_{s t}, \hat{y}_{m t}$ and $\hat{y}_{a t}$ are, respectively,

$$
\begin{aligned}
\frac{\theta y_{t}}{\hat{y}_{s t}} & =p_{s t} \\
\frac{\gamma y_{t}}{\hat{y}_{m t}} & =p_{m t} \\
\frac{(1-\gamma-\theta) y_{t}}{\hat{y}_{a t}} & =p_{a t}
\end{aligned}
$$

Firms in the manufacturing sector choose $k$ and $l_{m}$ to maximize profits subject to the production technology. Their first order conditions are

$$
\begin{aligned}
\alpha p_{m t} \frac{y_{m t}}{k_{t}} & =r_{t} \\
(1-\alpha) p_{m t} \frac{y_{m t}}{l_{m t}} & =w_{t}
\end{aligned}
$$

The first equation above is the optimal capital-use condition while the second condition determines optimal labor use. Lastly, agriculture and service sector firms choose labor to maximize profits. Their optimality conditions are

$$
\begin{aligned}
\mu p_{a t} \frac{y_{a t}}{l_{a t}} & =w_{t} \\
\sigma p_{s t} \frac{y_{s t}}{l_{s t}} & =w_{t}
\end{aligned}
$$




\subsection{Equilibrium conditions}

Noting that the final good and the services good are non-traded, the market clearing conditions for these goods dictates that their domestic consumption must equal their domestic production. Hence, we must have

$$
\begin{gathered}
c_{t}+k_{t+1}=y_{t}+(1-\delta) k_{t} \\
\hat{y}_{s t}=y_{s t}
\end{gathered}
$$

We also have a balanced trade condition that follows from the budget constraints and market clearing conditions. For each state we must have

$$
p_{a t}\left(y_{a t}+T_{a t}-\hat{y}_{a t}\right)=p_{m t}\left(\hat{y}_{m t}-y_{m t}-T_{m t}\right)
$$

Hence, net exports of agricultural goods, inclusive of transfers, must equal net imports of manufactured goods, also inclusive of transfers. In other words, exports must equal imports period-by-period.

Substituting in the market clearing condition for services into equation (6), one can solve for the state-specific price of services, $p_{s}$. In turn, one can use $p_{s}$ along with the zero profit condition for the final goods sector (and the normalization that the final good is the numeraire) to solve for $p_{m}$. Thus, we have

$$
\begin{aligned}
p_{s t} & =\frac{\theta y_{t}}{y_{s t}} \\
p_{m t} & =\left[\Gamma\left(\frac{p_{a t}}{p_{m t}}\right)^{\theta+\gamma-1} p_{s t}^{-\theta}\right]^{1 / 1-\theta} \quad, \quad \Gamma \equiv \theta^{\theta} \gamma^{\gamma}(1-\gamma-\theta)^{1-\gamma-\theta}
\end{aligned}
$$

In the light of the above, we can use the first order conditions (3)-(5), and (9)-(12) to derive 
the following set of equilibrium relationships:

$$
\begin{aligned}
\frac{p_{a t}}{p_{s t}} & =\left(\frac{\sigma}{\mu}\right) \frac{y_{s t} / l_{s t}}{y_{a t} / l_{a t}} \\
\frac{p_{s t}}{p_{m t}} & =\left(\frac{1-\alpha}{\sigma}\right) \frac{y_{m t} / l_{m t}}{y_{s t} / l_{s t}} \\
\frac{\chi c_{t}}{\bar{l}-l_{t}} & =(1-\alpha) p_{m t} \frac{y_{m t}}{l_{m t}} \\
\frac{c_{t+1}}{c_{t}} & =\beta\left(\alpha p_{m t+1} \frac{y_{m t+1}}{k_{t+1}}+1-\delta\right)
\end{aligned}
$$

Lastly, we can compute the sectoral productivity levels (in labor augmenting form) as

$$
\begin{aligned}
X_{a t} & \equiv x_{a t}^{\mu}=\frac{y_{a t}}{l_{a t}^{\mu}} \\
X_{m t} & \equiv x_{m t}^{1-\alpha}=\frac{y_{m t}}{k_{t}^{\alpha} l_{m t}^{1-\alpha}} \\
X_{s t} & \equiv x_{s t}^{\sigma}=\frac{y_{s t}}{l_{s t}^{\sigma}}
\end{aligned}
$$

Equations (13)-(21) hold for each state under study at each date. Moreover, given our data, we can measure all the variables in each of these nine equations for each state and date.

Given data on final output and services output, we can use equations (13) and (14) to impute the equilibrium prices $p_{s}$ and $p_{m}$. The four key first-order-conditions of the model (for which we do have the appropriate quantity data) are given by equations (15)-(18). ${ }^{10}$ Following Cole and Ohanian (2004) we can divide the left hand side of each first order condition by the corresponding right hand side to get a measure of the deviation of that condition from the optimum. Thus, for each margin we get one wedge for each state for

\footnotetext{
${ }^{10}$ We should note that there are two additional first order conditions given by equations (8) and (7). Given the relative price $p_{a} / p_{m}$ we can use these two conditions to solve for $\frac{\hat{y}_{a}}{\hat{y}_{m}}$. Given $y$ and $y_{s}$, one can then use the production function for final goods to solve for $\hat{y}_{a}$ and $\hat{y}_{m}$ individually. Substituting these into the balanced trade condition one can deduce the implicit values of transfers $T=p_{a} T_{a}+p_{m} T_{m}$ that would make the national income accounting hold exactly.
} 
every date. In particular, we have

$$
\begin{aligned}
\theta_{t}^{l, a s, i} & =\frac{p_{a t}}{p_{s t}} \frac{\mu y_{a t} / l_{a t}}{\sigma y_{s t} / l_{s t}} \\
\theta_{t}^{l, s m, i} & =\frac{p_{s t}}{p_{m t}} \frac{\sigma y_{s t} / l_{s a t}}{(1-\alpha) y_{m t} / l_{m t}} \\
\theta_{t}^{l, i} & =\frac{\frac{\chi c_{t}}{l-l_{t}}}{(1-\alpha) p_{m t} \frac{y_{m t}}{l_{m t}}} \\
\theta_{t}^{I, i} & =\frac{c_{t+1}^{i}}{c_{t}^{i} \beta}\left[\frac{1}{\alpha p_{m t+1} \frac{y_{m t+1}}{k_{t+1}}+1-\delta}\right]
\end{aligned}
$$

where $i=$ West Bengal, Maharashtra. $\theta^{l, a s, i}$ is the wedge in the optimality condition for labor allocation between agriculture and services while $\theta^{l, s m, i}$ is the corresponding wedge in the labor allocation between service and manufacturing sectors. A number less than one for the latter wedge, for example, would indicate that the marginal product of labor in manufacturing is too high. Note that the wedge in the optimal labor allocation condition between agriculture and manufacturing is given by the ratio $\frac{\theta_{t}^{l, a s, i}}{\theta_{t}^{l, s m, i}} . \quad \theta^{l, i}$ is the wedge in the optimal labor-leisure condition with numbers less than one indicating that the marginal product of labor is higher than the marginal disutility from labor. ${ }^{11}$ Lastly, $\theta^{I, i}$ is the wedge in the intertemporal Euler equation with a number below one indicating that savings are sub-optimally low. Note that since we do not have state-specific interest rate data, we have chosen to substitute the marginal product of capital into the Euler equation (4). Hence, assessing whether or not the Euler equation holds is actually a joint assessment of the Euler equation and the firm's optimal capital conditions holding simultaneously.

At this point it is worth noting that our framework implies that the difference in per

\footnotetext{
${ }^{11}$ Note that the measurement of the wedge in the optimal labor-leisure condition, $\theta^{l, i}$, is itself sensitive to the wedges in the inter-sectoral labor allocation conditions. Thus, if $\theta^{l, s m, i}$ is systematically different from unity then the measured $\theta^{l, i}$ would depend on whether we use the value marginal product of labor in agriculture, manufacturing or services in the denominator of the expression for $\theta^{l, i}$.
} 
capita output across states is attributable to either wedges in the first order conditions or productivity differences between the states. If all the wedges were one and there were no productivity differences, then, by construction, per capita output would be identical across the states. Alternatively, if there were no wedges in the first order conditions, then the entire difference in per capita output between West Bengal and Maharashtra would be attributed to productivity differences. In this event, steady state levels of labor supply and capital per efficiency unit of labor, $k$, would be the same across the two states. The only difference would be in the levels of the per capita variables and wages. On the other hand, if there are wedges in one or more of the first order conditions then the steady state allocations of the stationary variables would be different across the states.

Recall that owing to data limitations, services and agricultural output are modeled as a function of labor only. This means that the productivity term includes both TFP and capital. Hence, to the extent forces like credit constraints, social networks, and lack of appropriate regulations lead to inefficiently low capital, it will show up in the productivity numbers for these two sectors. Banerjee and Duflo (2004) and Banerjee and Munshi (2004) discuss how micro misallocation issues can lead to aggregate shortfalls in investment and capital.

We compute the wedges by using the follow standard values for the key parameters of the model: 


\begin{tabular}{l|l} 
Parameter & Value \\
\hline \hline$\alpha$ & 0.3 \\
$\mu$ & 0.45 \\
$\sigma$ & 0.7 \\
$\theta$ & 0.4 \\
$\gamma$ & 0.2 \\
$\beta$ & 0.96 \\
$\bar{l}$ & 5000 hours \\
$\psi$ & 2.24 \\
$\delta$ & 0.04
\end{tabular}

Some of the our parameter values need elaboration. The parameter values for $\beta$ and $\delta$ are standard. $\psi$ and $\bar{l}$ are taken from Chari, Kehoe and McGrattan (2004). We picked $\theta$ and $\gamma$, the shares of services and manufacturing in total output based on the average shares of these sectors in total output in these two states during the period 1960-95. The parameters $\alpha, \mu$ and $\sigma$ are more problematic, because we do not have estimates of these parameters. We set $\alpha=0.3$ and $\sigma=0.3$ based on Abler, Tolley, and Kripalani (1994) who estimated the capital share of the non-agricultural sector to be 0.3. Abler, Tolley, and Kripalani also estimated the labor share in Indian agriculture to be 0.45 which is the number we chose for $\mu$.

Figures 8-10 show the evolution of the two sectoral labor allocation wedges and the Euler equation wedge respectively from 1960 to 1995 . In all three pictures we measure the statespecific wedges on the left axis and the relative wedge (measured as the ratio of the West Bengal wedge to the Maharashtra wedge) on the right axis. There are three key messages 
that emerge from these figures. First, the wedge in the optimal labor allocation condition between agriculture and services (Figure 8) behaved very similarly in the two states during this period. This is clear from the fact that the relative wedge in 1995 was almost identical to its value in 1960. Thus, labor misallocation between agriculture and services is not a factor in understanding the differential performance of the two states during this period. ${ }^{12}$ Second, the wedge depicted in Figure 9 shows that the marginal product of labor in manufacturing was too low relative to the services sector in both states. However, in Maharashtra by the end of the period the wedge was approaching unity, i.e., the optimal point in a frictionless labor market. In West Bengal, the wedge rose initially, and then fell. By 1995, it was only slightly lower than its value in 1960. Hence, manufacturing labor productivity remained too low. As a result, the West Bengal wedge relative to the Maharashtra wedge rose from about one in 1960 to almost three by 1995. Thus, low labor productivity in manufacturing appears to have been an important part of the differential evolution of the states. ${ }^{13}$ Third, Figure 10 shows that the Euler equation held fairly well over this period, because the investment wedge was reasonably close to one for most of the time for both states. Note that in the light of footnote 10 above and the fact that the observed wedges in inter-sectoral labor allocations are systematically different from one, we ignore the measured labor wedge $\theta^{l}$.

We next turn to the evolution of the sectoral productivity factors in the two states.

\footnotetext{
${ }^{12}$ The fact that the wedge for each state is significantly lower than unity reflects a well known characteristic of developing countries: the excess concentration of the workforce in agriculture. The key point here is that this margin did not worsen during the period, nor did it differ across the two states.

${ }^{13}$ Note that since the wedge in labor allocation between agriculture and services remained relatively stable in both states while the wedge between services and manufacturing increased, it follows that the wedge between agriculture and manufacturing also increased during the period 1960-95 (because it is a ratio of the first two wedges).
} 
Figure 8: Labor allocation wedge between agriculture and services

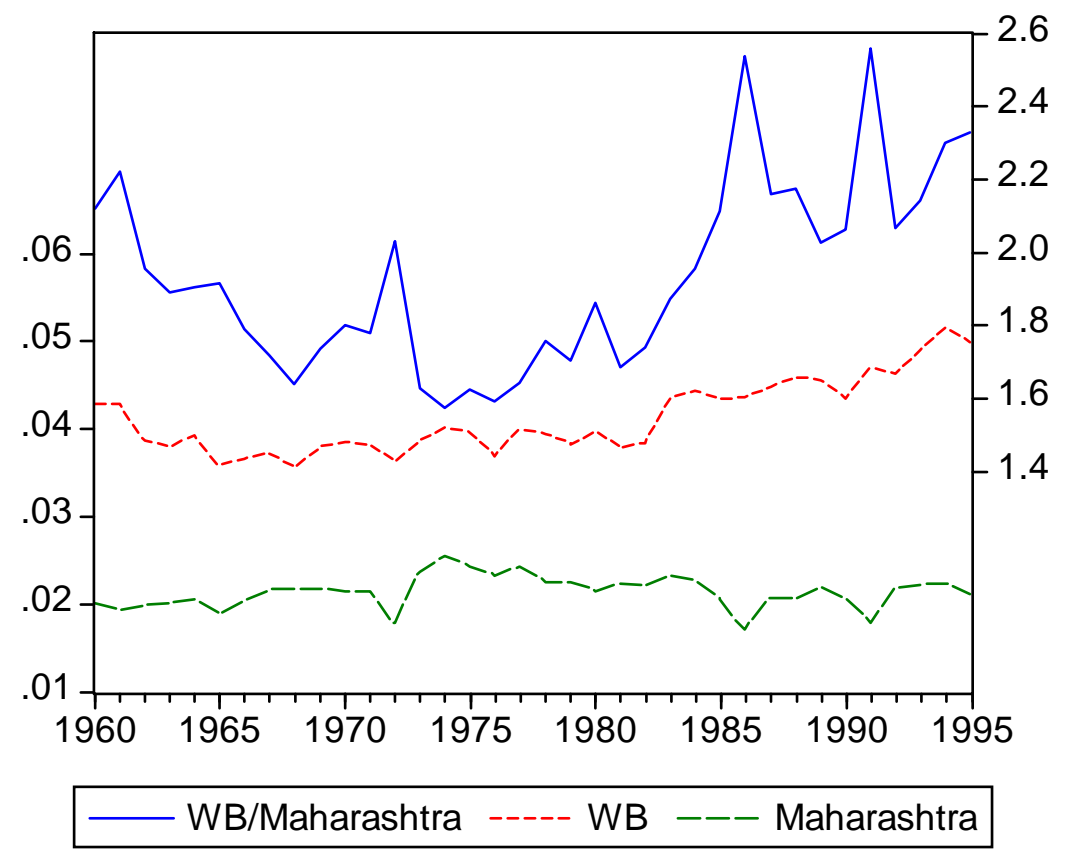

Figure 9: Labor allocation wedge between services and manufacturing

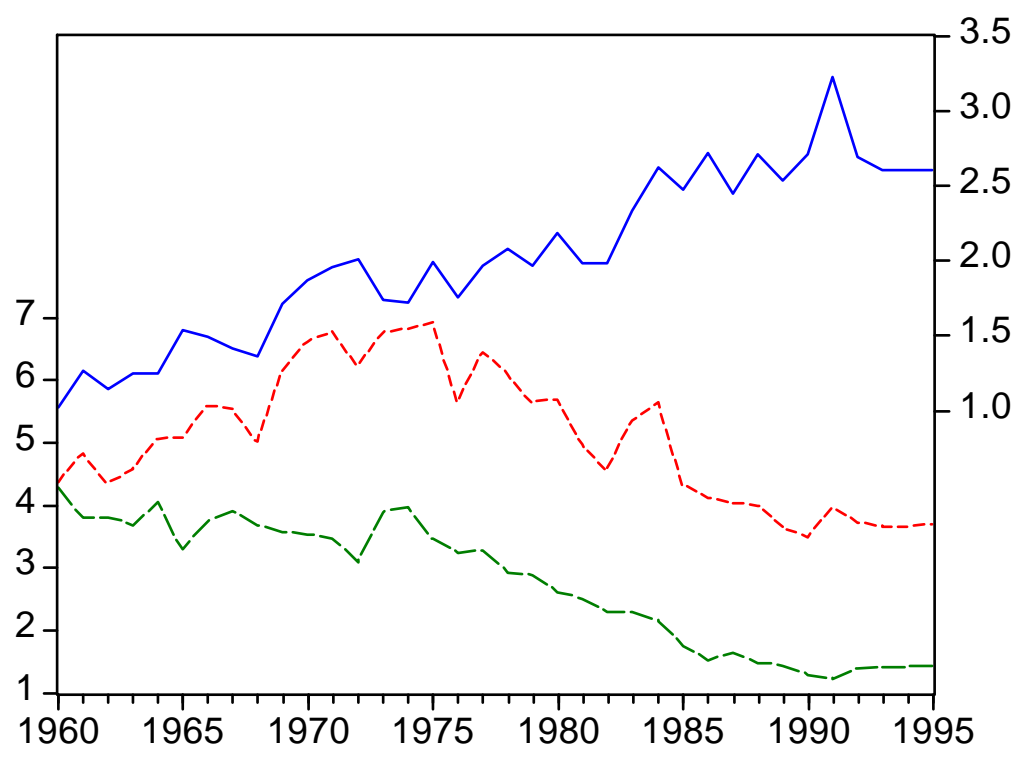

— WB/Maharashtra ----- WB --- Maharashtra 
Figure 10: Intertemporal savings wedge

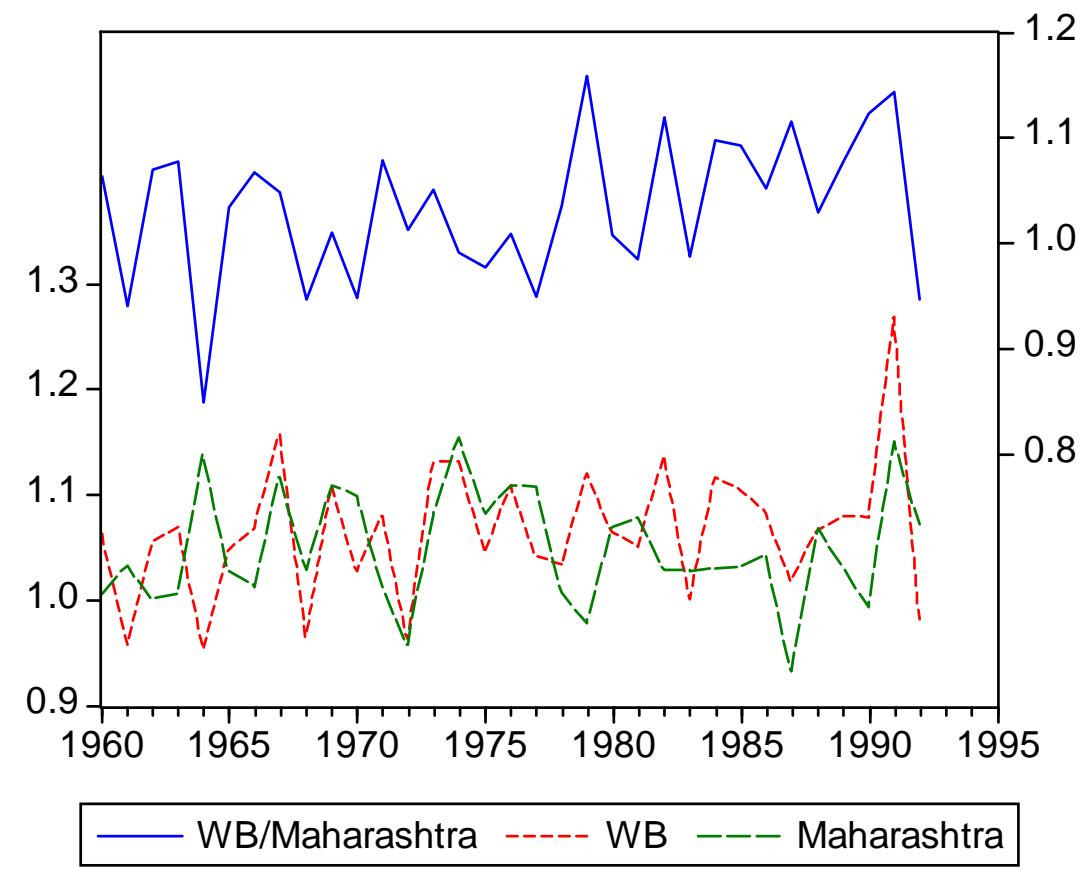

Figures 11-13 show the evolution of productivity measured in labor augmenting form in agriculture, manufacturing and services sectors. As before we measure the state-specific productivities on the left axis and the relative sectoral productivity of West Bengal on the right axis. Agricultural productivity behaved very similarly in the two states. Agriculture in both West Bengal and Maharashtra became more productive; hence, the relative position changed little during this period. The picture is quite different in the manufacturing and services sectors. In manufacturing, West Bengal's productivity declined from 80 percent of Maharashtra in 1960 to about 30 percent by 1995. The figure shows that West Bengal's manufacturing productivity was essentially stagnant during this period. Similarly in the services sector, West Bengal's productivity declined from about 90 percent of Maharashtra's productivity in 1960 to about 55 percent in 1995. Unlike in manufacturing, West Bengal's 
Figure 11: Agricultural productivity

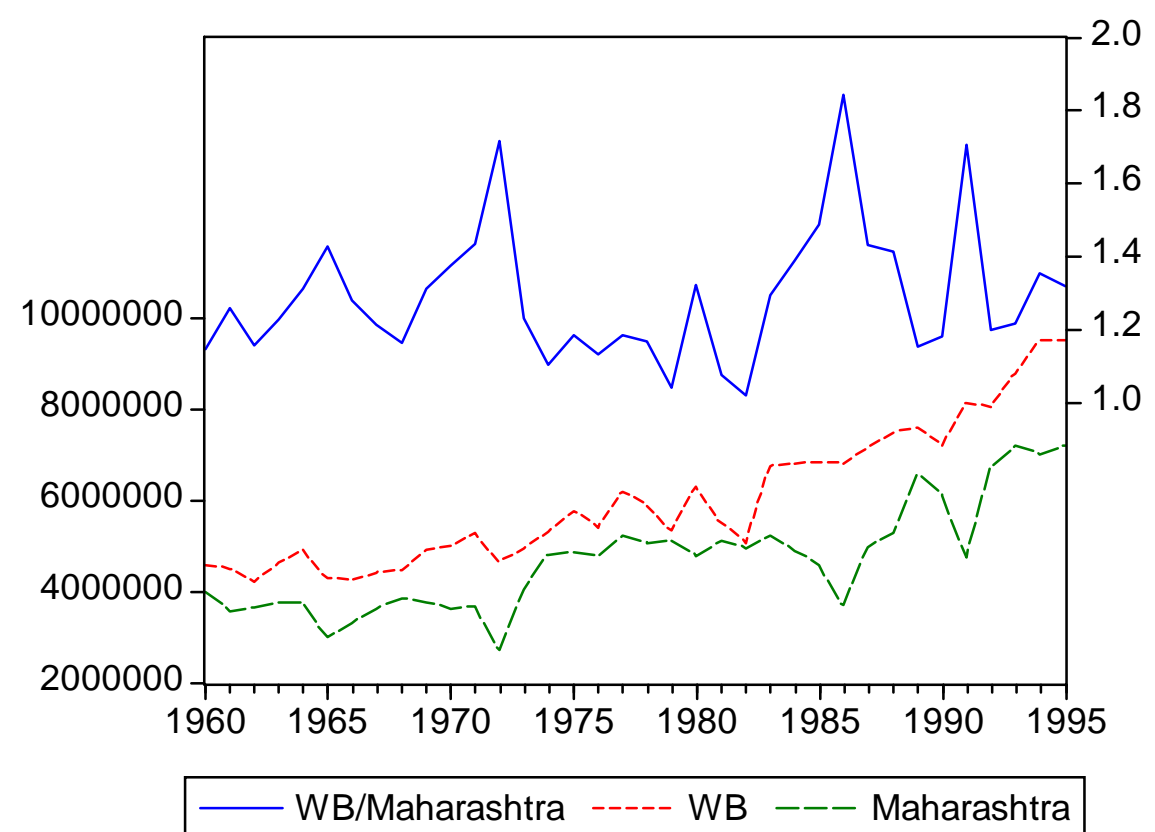

productivity in services did grow; Maharashtra's productivity just grew faster, especially from the late 1980s onward.

Our calculations above imply that West Bengal's manufacturing productivity relative to Maharashtra's manufacturing productivity fell by 52 percent between 1960 and 1995. During the same period, West Bengal's real manufacturing output relative to Maharashtra fell from 0.8 to 0.15 , a decline of 80 percent. Consequently, differences in manufacturing productivity account for 52/80 or 65 percent of the decline in West Bengal's relative real manufacturing output. Our diagnostic exercises above suggest that the remaining 35 percent decline in relative manufacturing output is attributable to labor market problems, possibly distortions. Contrastingly, in the services sector, West Bengal's productivity and real output (relative to Maharashtra) both declined by about 39 percent between 1960 and 1995. Thus, differences 
Figure 12: Manufacturing productivity

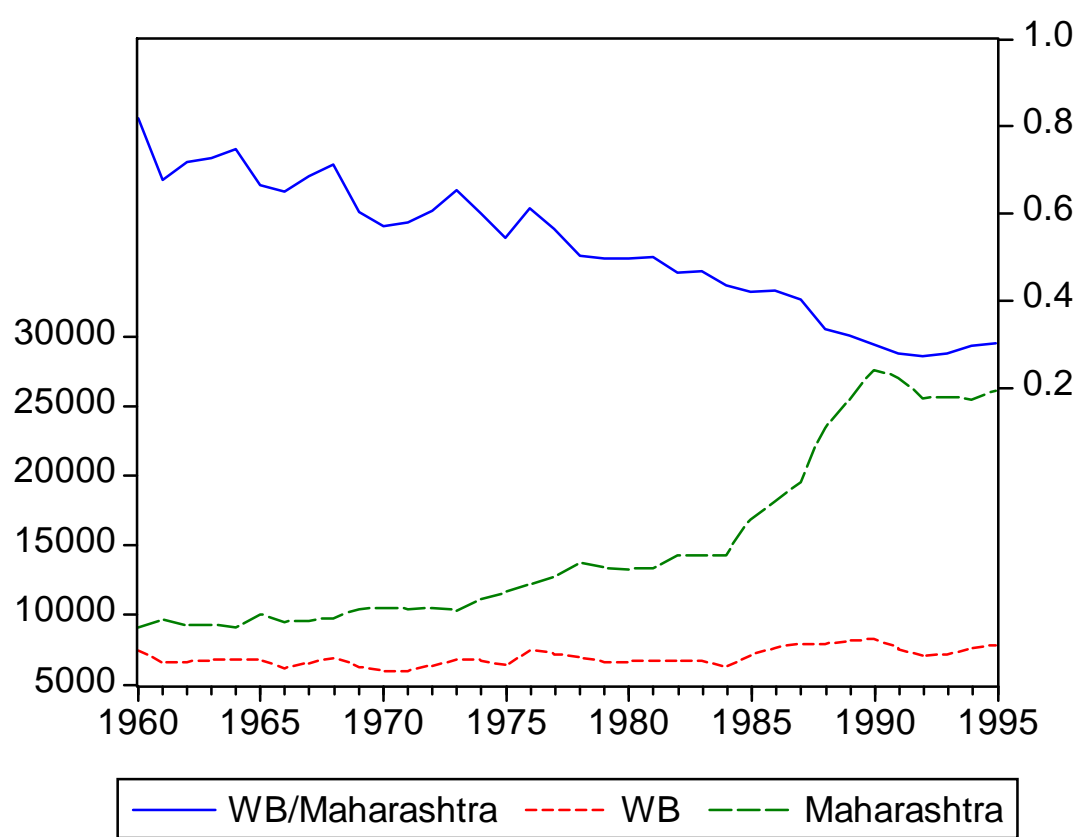

Figure 13: Services producivity

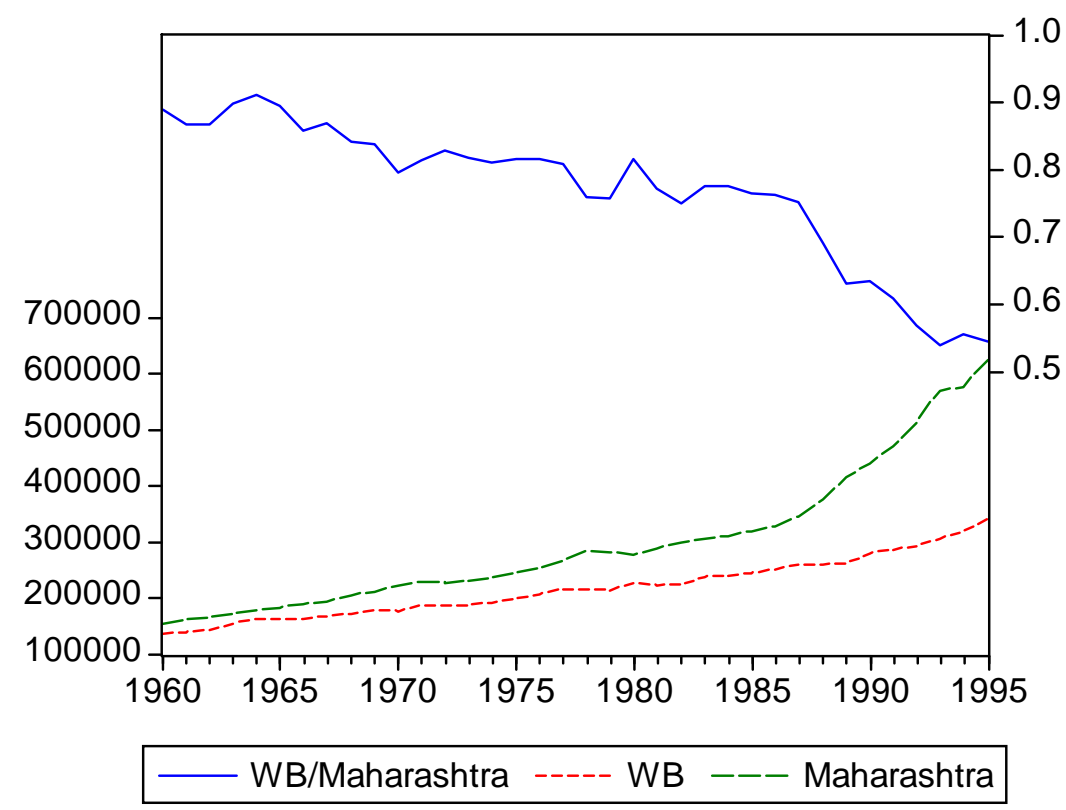


in services productivity account almost entirely for the different evolution of relative services output in the two states during this period. ${ }^{14}$

The agricultural sector reveals a picture very different from the other two sectors. While relative agricultural productivity in West Bengal increased by a relatively small 15 percent between 1960 and 1995, relative real agricultural output actually increased about 34 percent during the period. Hence, productivity increases In West Bengal accounted for only about 44 percent of the increase in its relative real agricultural output during this period. The rest came due to factors which caused a 30 percent increase in West Bengal's relative agricultural employment. This would be consistent with pro-agricultural labor force factors occurring during this period.

\section{Proximate Explanation}

Having described the economic dynamics in the two states, we now turn to studying one potential explanation for the observed disparity between the West Bengal and Maharashtra. In this we will be guided by the diagnostic exercises carried out above. Of particular interest to us is to identify factors specific to West Bengal that could have simultaneously depressed total factor productivity in manufacturing and services, reduced the marginal product of labor in manufacturing, and increased incentives for labor employed in agricultural in the state. $^{15}$

\footnotetext{
${ }^{14}$ Note that in the multi-sector model, human capital differences would show up as produtivity differences. This is the reason we do not use "TFP" in this section. Our accounting results in section 2 suggest that most of West Bengal's relative decline in manufacturing and services productivity is due to TFP, however.

${ }^{15}$ The usual practise in exercises like these is to look for specific policies that could have caused these outcomes. The complicating factor here is the compulsion of electoral politics in India. The strong socialistic bent of the country since gaining independence from Britain in 1947 has caused political parties
} 
In order to make some progress, we start by looking for signs of rising bargaining power of the trade unions in West Bengal. This may have induced more aggressive trade union demands for higher wages, more labor-friendly work rules etc.. To examine this possibility, in Figure 14 we look at the ratio of mandays lost to mandays worked in West Bengal and Maharashtra between 1960 and 1995. The figure is revealing. The level of industrial action in the two states was almost identical till 1966. Starting in 1967 there was a sharp spike in industrial action in West Bengal. Thereafter the mandays lost ratio in West Bengal was always higher than in Maharashtra (with the exception of one year, 1982, which saw a brutal strike in Maharashtra). During the period the mean for the mandays lost ratio in West Bengal was almost three times that in Maharashtra. ${ }^{16}$

What factors could have been associated with the rising power of trade unions in West Bengal? To better understand this, it is important to describe the political history of West Bengal. Since 1977 West Bengal has been governed uninterrupted by a leftist coalition called the Left Front led by the Communist Party of India (Marxist) making it the longest across most of the ideological spectrum to converge on a similar set of stated economic policy goals. These stated goals typically include being pro-labor, pro-rural, pro-agriculture, pro-small scale industries, etc. Hence, examining stated policies across states in India often doesn't reveal the true picture. Thus, even though Besley and Burgess (2004) found that West Bengal was the state with the highest number of prolabor changes in labor regulations, they ended up classifying both West Bengal and Maharashtra as being pro-labor. Rather, in our opinion, the key difference across states is the implementation record: which policies are implemented and how rigorously are they implemented. But this is precisely what makes the mapping between policies and outcomes hard.

${ }^{16}$ To put these numbers in perspective, it is worth noting that Maharashtra was not exactly a state with a particularly docile labor force. The level of trade union power in the textile industry in Maharashtra was extremely high with some of the state trade union leaders like Mr. Datta Samant having a national profile. 
Figure 14: Mandays lost due to industrial action

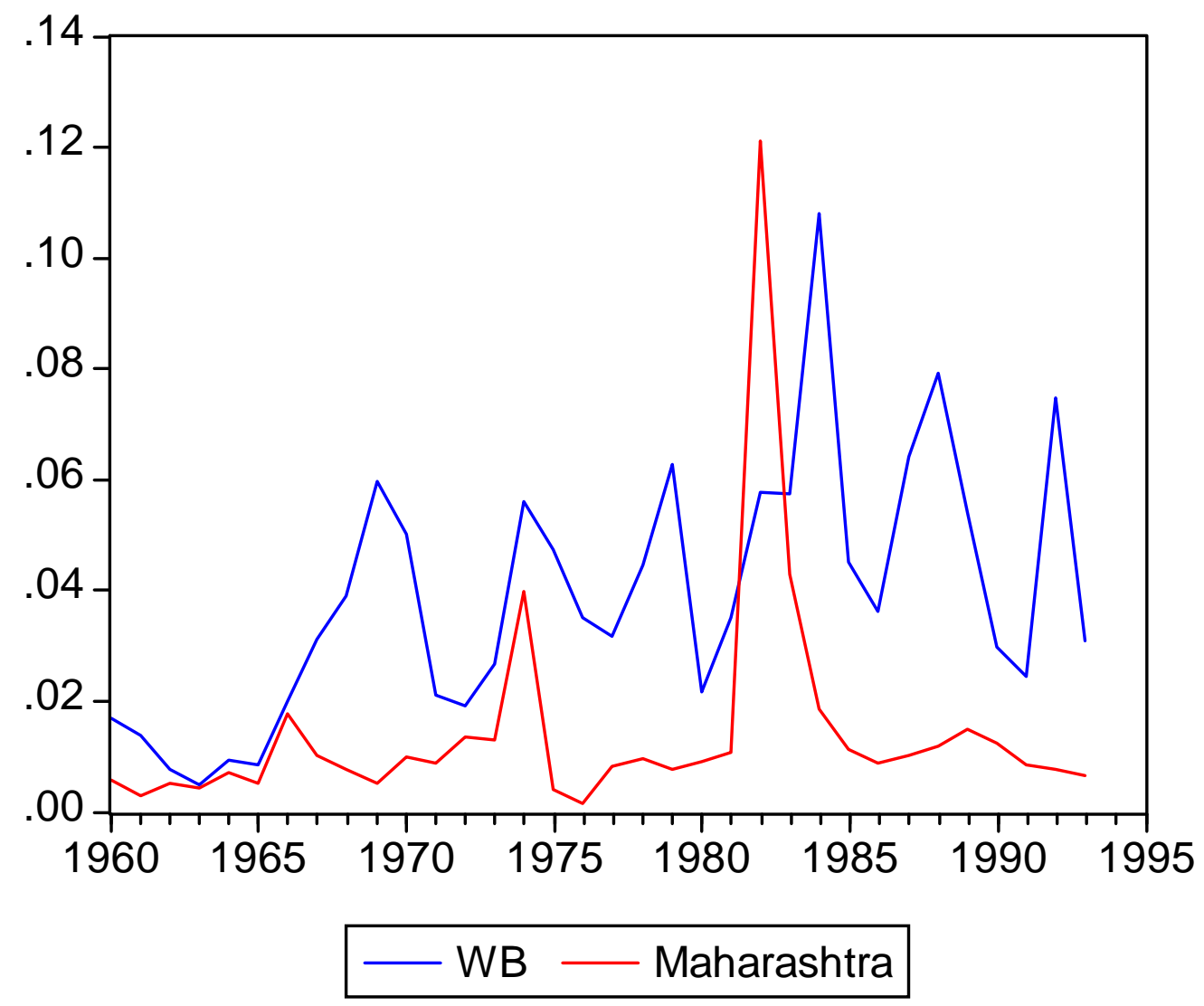


running government in the country. ${ }^{17}$ It is instructive to note that the leftist vote share in West Bengal grew rapidly from 18 percent in 1951 to 32 percent in 1962 to 46 percent in 1971 to 49 percent in 1995. The fact that days lost due to industrial action in West Bengal started rising in the late 1960s is interesting as that was precisely the time that the leftist coalition first came to power in the state, albeit for a short period of time. In 15 we plot the leftist vote share against the ratio of mandays lost to mandays worked in West Bengal. As is obvious, the more powerful the left became the greater was the incidence of labor action, strikes etc. - the correlation between the leftist vote share and mandays lost ratio is 0.59. Another sign of increasing labor power in West Bengal during this period was rapid expansion in the number of registered trade unions in West Bengal from 2057 in 1957 to 4808 in 1970, i.e., a 2.5 fold rise. During the same period the number of registered trade unions in Maharashtra only increased from 1586 to $2560 .^{18}$

Since the Leftist political parties are the biggest supporters of labor and the rural poor, one candidate explanation for the differential performance between the two states is that the politics of West Bengal caused it. It is important to reiterate that despite the similarity

\footnotetext{
${ }^{17}$ With the exception of some brief interludes, between 1960 and 1995 Maharashtra was governed almost throughout by the Congress party. The Congress party was also the ruling party at the federal level during most of this period. The prevailing ideology of the Congress party was socialism with a strong belief in the paternalistic role of the state, self-reliance, infant industry protection etc.. Until 1977, West Bengal's political history reads very much like Maharashtra's with the state being ruled almost throught by the Congress party (except for a short two year interlude between 1969 and 1971 when a leftist coalition called the United Front ruled the state government).

${ }^{18}$ Unfortunately, our data on trade unions in West Bengal does not extend beyond 1970 . The numbers on trade unions take on additional meaning once it is noted that after 1965 a significant fraction of manufacturing output in West Bengal shifted into the un-registered sector which was theoretically free of trade unions.
} 
Figure 15: Leftist vote share and industrial action in West Bengal

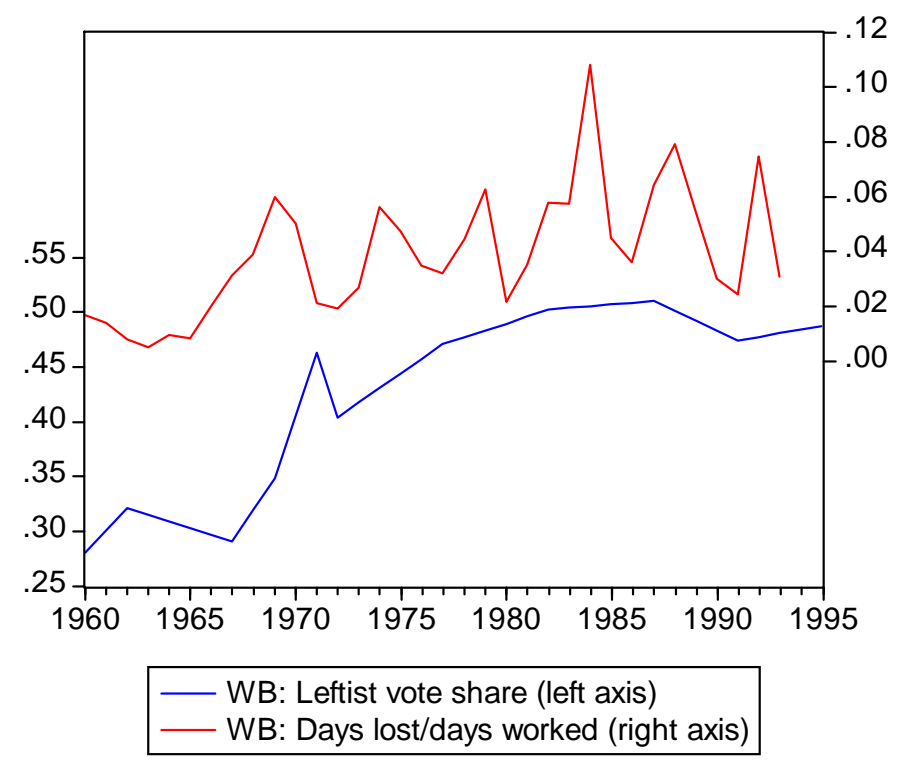

between the stated political and economic objectives of both the leftist parties as well as the socialism oriented Congress party, there may well be a difference in policy implementation between a government run by a party that courts labor votes and a government that is run by labor interests itself. We assess the potential of this margin by examining the interaction of the political power of the left with the wedges that we identified above.

In Figures 16 and 17 we plot the vote share of the Leftist parties in West Bengal along with the two labor allocation wedges involving the manufacturing sector: agriculture to manufacturing, and services to manufacturing. The correlation of the vote share with the two wedges is 0.69 and 0.85 respectively. ${ }^{19}$ We do not plot the vote share with the

\footnotetext{
${ }^{19}$ The leftist vote share is defined as the combined vote share in local Assembly elections of the following parties: Communist Party of India, Communist Party of India (Marxist-Leninist), Communist Party of India (Marxist-Leninist) (Liberation), Communist Party of India (Marxist), Forward Block, Forward Block (Socialist), Farward Block, Forward Block (MG), Forward Block (RG), Forward Block (Marxist), Revolu-
} 
Figure 16: Leftist vote share and Agriculture/manufacturing wedge

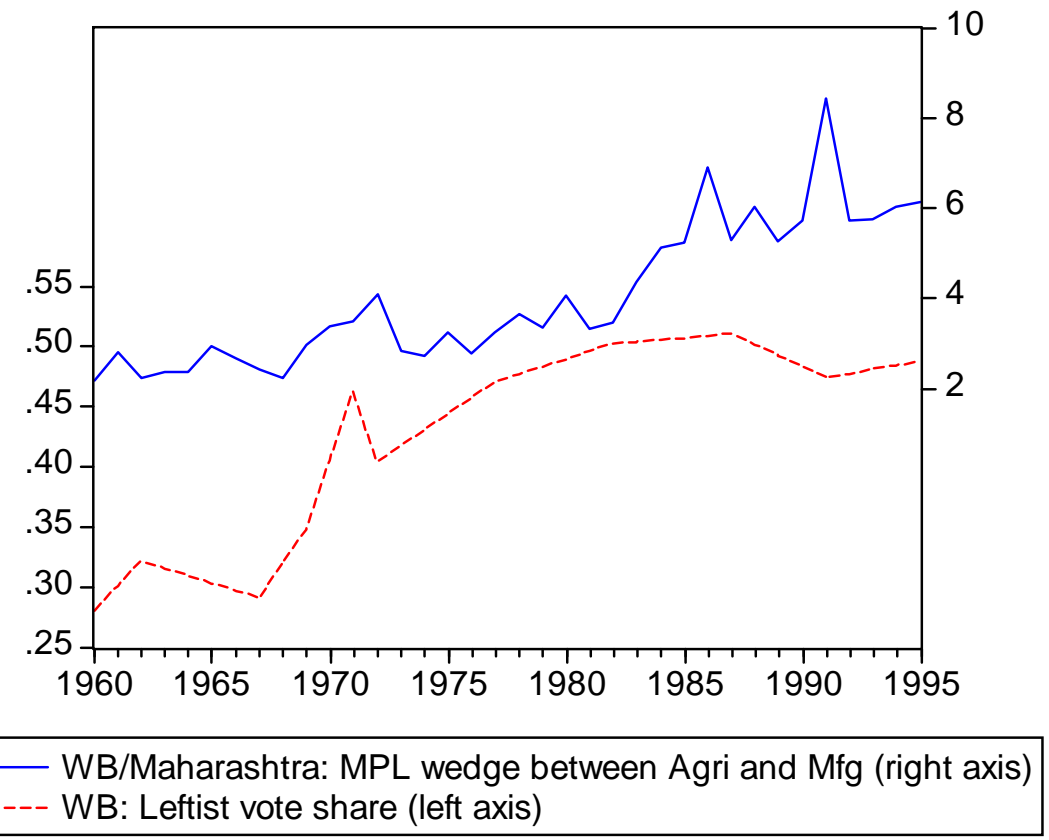

agriculture/services labor allocation wedge and with the savings (Euler equation) wedge, because we have already seen that these two wedges did not show much movement during the period under study.

In Figures 18 and 19 we plot the Leftist vote share against the productivity wedges in the manufacturing and services sectors in West Bengal (relative to Maharashtra). The figures show a strong negative relationship between the vote share and the wedges with correlations of -0.82 and -0.67 , respectively. Clearly, leftist votes didn't translates into productivity gains tionary Socialist Party. We have data for the Assembly elections in 1951, 1957, 1962, 1967, 1971, 1972, 1977, 1982, 1987, 1991, 1996, and 2001. We generated an annual series for the vote share by filling in for the years between elections using the average annual growth rate of the share between successive elections. 
Figure 17: Leftist vote share and Service/manufacturing wedge

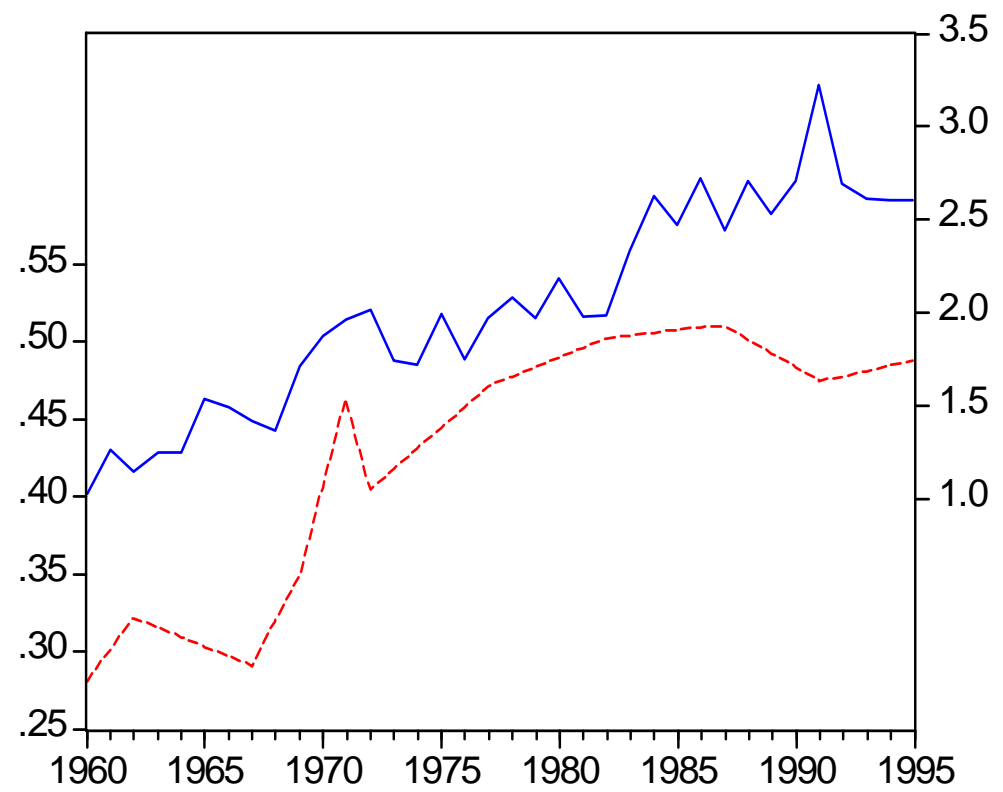

— WB/Maharashtra: MPL wedge between Services and Mfg (right axis) ---- WB: Leftist vote share (left axis) 
Figure 18: Leftist vote share and relative manufacturing productivity in West Bengal

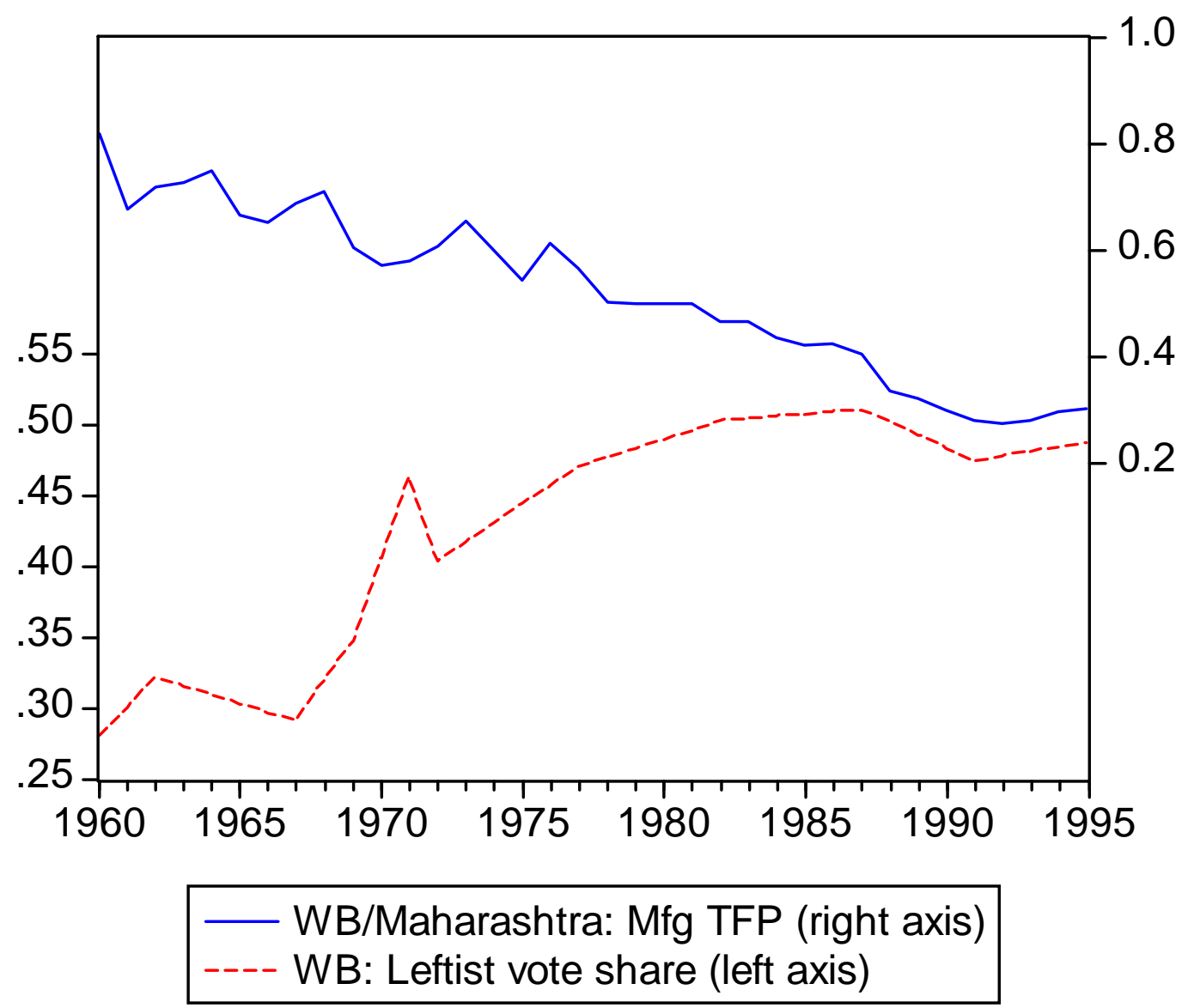

in general.

\section{Conclusions}

In this paper, we have contrasted the development paths of two Indian states, West Bengal and Maharashtra, between 1960 and the mid-1990s. Starting from an initial position of about 5 percent greater per capita output than Maharashtra, West Bengal's per capita output had dropped to about 69 percent of Maharashtra by 1993. Our relative levels accounting suggests that differences in TFP account for about 60 percent of the gap between West Bengal and 
Figure 19: Leftist vote share and relative services productivity in West Bengal

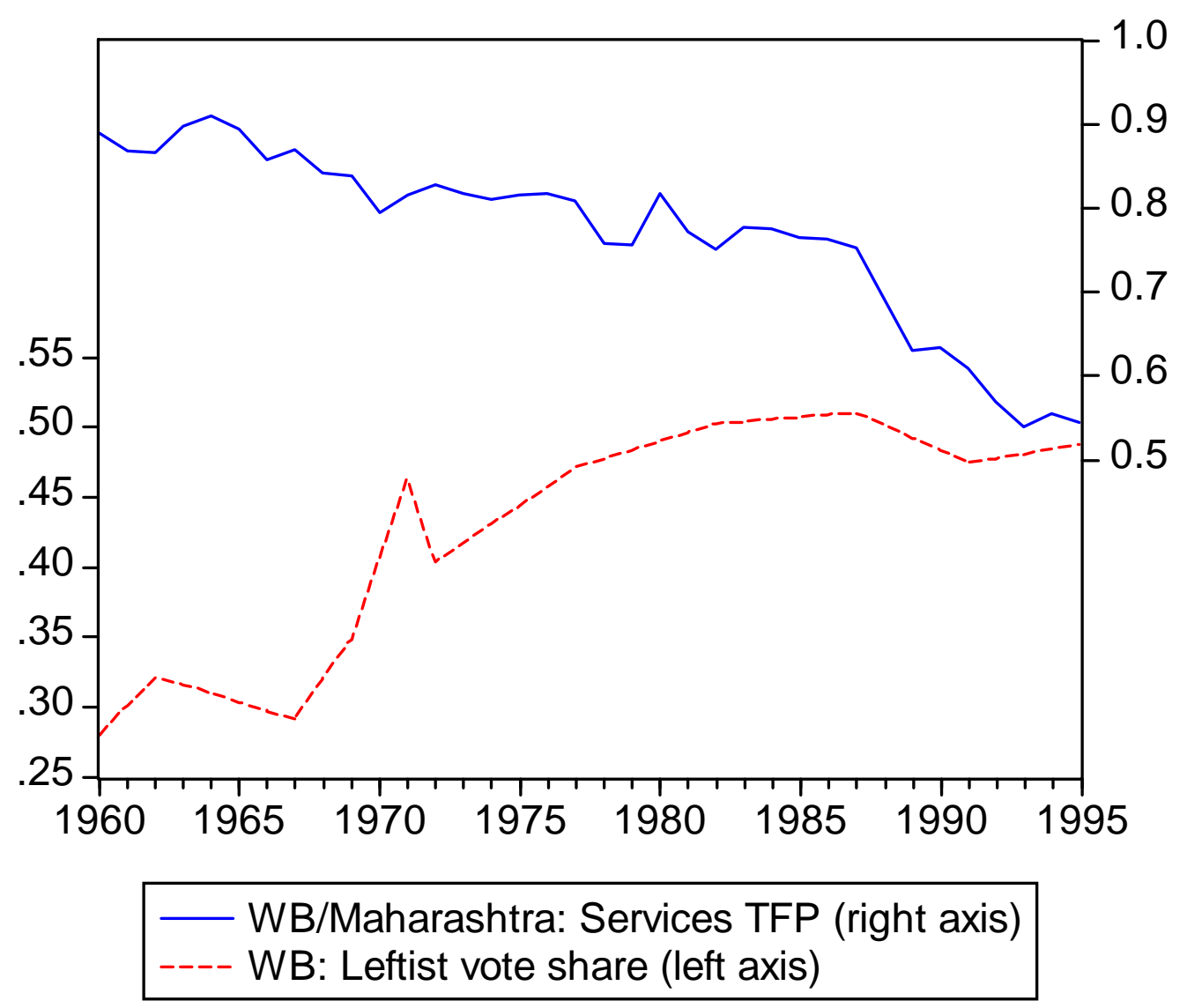


Maharashtra, relative to their positions in 1961. Human capital accounts for a little more than 20 percent of the gap and physical capital accounts for the remainder. In terms of sectors, manufacturing, in particular, appeared to lose ground in West Bengal.

We have also used a multi-sector model to conduct model-based diagnostic tests. Our multi-sectoral tests suggest that productivity differences - attributable to both TFP and human capital - account for about $3 / 4$ of the gap between the states. The remainder is likely to be due to problems in the labor market in West Bengal. In particular, there appear to have been some factor(s) that raised wages in West Bengal above the levels dictated by the neoclassical growth model's first order conditions. The strong correlations of our estimated labor market and productivity wedges with the vote share of the Leftist parties in West Bengal suggest that increasing labor power during this period in West Bengal may have been the proximate cause of the diverging economic performance of the two states.

While the diagnostic exercises in the paper suggest that the problems are likely to be in the labor market, in order to assess the quantitative importance of this margin one needs to formalize and quantify a political-economy model in which declining investment and output can coexist with rising labor power for relatively sustained periods of time in a voting environment. This is the subject of our future work in this area.

\section{A Data Appendix}

Our data come from numerous sources. The primary sources are the Census of India for 1961, 1971, 1981, and 1991, and three CD-ROMs from the Economic and Political Weekly (EPW) Research Foundation database ("Domestic Product of States of India, 1960-61 to 2000-01", "National Account Statistics of India, 1950-51 to 2000-01", and "Annual Survey of Industries, 1973-74 to 1997-98"). Data on population, employment, and schooling are 
drawn from the Census. Data on net state domestic product (NDP), sector-level NDP, and all-India capital, draw from EPW. Most of this data is available in current prices and constant prices.

We also use the World Bank data base created by Ozler, Datt, and Ravallion (1996), primarily for measures of price indices that control for inter-state price differentials. The World Bank data set also provides data on consumption, registered and un-registered manufacturing production, manufacturing employment, and manufacturing capital. The World Bank manufacturing data is supplemented by manufacturing data from Besley and Burgess (2004). (We thank Robin Burgess for sending us his data.) Lastly, we use data from Deb (2002) for our data on the relative price of agriculture. We now describe the data sources and variable construction (further details are available from the authors on request):

\section{A.1 Key Stylized Facts Section}

The real per capita NDP numbers underlying Figures 1 and 2 were constructed in three main steps. First, several constant-price NDP series were spliced together. For the time period 1960-61 through 1993-94 (hereafter, "1960" means "1960-61"), there are four constant-price NDP series, each based on prices for a particular year (1960, 1970, 1980, and 1993) and each covering a subset of the overall period. The splicing procedure involves two parts. First, for years in which more than one constant-price NDP series exist, the more recent NDP series are used. Second, to convert the 1980 series into 1993 prices, a conversion factor is needed. This conversion factor is obtained by finding the first year that two series has in common, e.g., 1993, and then dividing NDP in 1993 measured in 1993 prices by NDP in 1993 measured in 1980 prices. This ratio is then used to convert all other years for which the 1980 constant-price series is the relevant series. A similar exercise is done for the other 
constant-price series. At the end, we have a single, real NDP series for each state measured in 1993 prices. Second, these series are divided by population. The population data is obtained from the Census. We linearly interpolate to obtain estimates of population for the non-Census years. Third, we multiply by an adjustment factor that facilitates cross-state comparisons. In particular, we use two consumer price indices (CPI) drawn from the World Bank data base. One CPI is for agricultural laborers and the other is for industrial workers. Both indices adjust for inter-state cost of living differences. ${ }^{20}$ We take a simple average of these two indices' values for 1993, and we then multiply this average by the constant-price NDP series. This renders the series comparable across states. In Figure 1, the "final" NDP per capita value is divided by the corresponding value for Maharashtra. In Figure 2, we add all states other than Maharashtra and West Bengal together to form the rest of India aggregate. The states include Andhra Pradesh, Assam, Bihar, Gujarat, Haryana, Punjab, Jammu and Kashmir, Karnataka, Kerala, Madhya Pradesh, Orissa, Rajasthan, Tamil Nadu, and Uttar Pradesh.

For our NDP per worker growth and relative levels decomposition exercise, we employ data on output, physical capital, human capital, and employment. Data on constant price NDP for West Bengal and Maharashtra are constructed as described above, except they are not multiplied by the adjustment factor, because we focus on relative comparisons and comparisons over time.

There is no state-level physical capital series. We impute this series using each state's current price sector-level NDP series and the all-India constant price sector-level net fixed capital stock series. We first calculate West Bengal's share of India's NDP in agriculture,

\footnotetext{
${ }^{20}$ See the documentation associated with Ozler, Datt, and Ravallion (1996) for more details on how these CPI indices were constructed.
} 
forestry and fishing, and then multiply that share by the all-India net fixed capital stock for agriculture, forestry and fishing. This yields a value for West Bengal's net fixed capital stock in this sector. We repeat for all sectors and then sum across sectors. We do the same for Maharashtra. Underlying this imputation is the assumption that production functions are the same across states and that prices of capital are equalized across states.

Human capital and employment are drawn from the India Census. For human capital we use the Census tables that classify workers by type and by level of education and that classify workers by industrial category and by level of education. This data divides the work force into several schooling categories. We convert these categories into years of schooling as follows. "Literate without any formal schooling/below primary": 2 years; "Primary": 5 years; "Middle": 8 years; "Matriculation/secondary": 10 years; "Higher secondary / intermediate / pre-university or non-technical/technical diploma or certificate not equal to degree": 12 years; "University degree or post-graduate degree other than technical degree/Technical degree of diploma equal to degree or post-graduate degree (includes engineering, medicine, and teaching): 16 years. ${ }^{21}$

From this data, the share of the worker population which has completed each level of education can be calculated for each census year. This vector of education weights is multiplied by $\phi(E)$ to obtain a measure of the log of human capital per unit labor.

Our functional form for $\phi(E)$ is piecewise linear and draws from Psacharopoulos (1994). for the first four years of education the rate of return is 13.2 percent, for the next four years the rate of return is 10.1 percent, and any year of schooling after that has a rate of

\footnotetext{
${ }^{21}$ Our calculations yield an average years of schooling for West Bengal and for Maharashtra in 1981 (1991) that are about a half-year below (a half year above) the India years of schooling number, based on 1985, from the Barro-Lee data set.
} 
return of 6.8 percent. In addition, we also employ rates of return estimated for India in 1983 by Duraisamy (2002): Primary (1-5 years), 8.2 percent; Middle school (6-8) years, 8.4 percent; Secondary school (9-12 years), 13.7 percent; College/University (13-17 years), 11.6 percent; Technical diploma/certificate (13-17 years), 13.4 percent. Using the latter rates of return yielded somewhat different measures of human capital, but nearly identical growth accounting results.

Measuring employment in each Census year is complicated by the fact that during the period we study, there were two major conceptual and definitional changes on the measurement of workers, one at the 1971 Census and one at the 1981 Census. In the 1971 Census, the underlying concept that differentiated a worker from a non-worker was changed from "labour time disposition" to "gainful occupation". In particular, the reference period for agricultural work was changed from the "greater part of the working season" to the entire year. This led to a decline in the all-India reported number of workers between 1961 and 1971 by almost 5 percent, a period in which India's population aged 15 and over increased by 23 percent! This decline was more than accounted for by a reported decline in female rural workers, which fell by 50 percent.

The second major conceptual changed occurred in 1981, in which workers were now categorized as main and marginal according to whether they worked for the major part of the year or not. The idea behind this was to come up with a concept similar to the 1971 Census but also to provide comparability with earlier Censuses. Thus the main workers concept in 1981 is comparable to the workers concept in 1971, and the main-plus-marginal workers concept in 1981 is broadly comparable to the workers concept in 1961.

There remains the issue of comparing 1961 and 1971. We adopt three approaches. The first is to use the originally reported Census numbers for 1961 and 1971, as well as "main" 
workers in 1981 and 1991. This is our benchmark. The second is to employ official adjustments made in 1971 to the 1971 Census and the 1961 Census to make them more compatible. In particular, a new sample was conducted late in 1971 in which participants were asked the questions from the 1961 census. The resulting outcome led to an adjusted 1971 census. In addition, the change in participation rates between 1961 and the adjusted 1971 census is used to created an adjusted 1961 census that are the values that ensure that the change in participation between adjusted 1961 and 1971 is the same as between 1961 and adjusted 1971. These adjustments provide two alternatives, then. One alternative uses the original 1961 numbers, the adjusted 1971 numbers, and the appropriate categories for 1981 and 1991 (main plus marginal workers). The second alternative uses the adjusted 1961 numbers, the original 1971 numbers, and the appropriate categories for 1981 and 1991 (main workers). The third approach is to employ adjustments along the lines of Abler, Tolley, and Kripalani (1994), who use data from the National Sample Survey (NSS) to impute a workforce for 1971. This adjustment essentially ties the number of workers more closely to the growth of the working age population.

Given that our primary goal is to compare West Bengal to Maharashtra, if the changing Census definitions over time do not affect West Bengal and Maharashtra differently, then the relative comparisons are unaffected. However, female participation rates in Maharashtra historically have been much higher than in West Bengal (in 1961 it was 38 percent compared to 8 percent). Thus, the underreporting of women had a larger effect on Maharashtra than on West Bengal. Consequently, for robustness, we employ all three approaches - the benchmark approach, as well as the three adjustments in the other two approaches.

The sectoral output shares presented in figure 4 are created from current price sectorlevel NDP data spliced in a similar manner to the constant price series discussed above. All 
sectors are included other than forestry and fishing, and mining. These data draw from the Domestic Product of States of India CD-ROM.

The manufacturing output, capital and employment data underlying figures 5-7 come from the Annual Survey of Industries CD-ROM and from Besley and Burgess (2004). This data is for registered manufacturing only. The output variable is net value added. The capital variable is fixed capital. Both variables are presented in current price terms. To convert to real and to facilitate comparisons across states, the series are deflated by the industrial workers CPI from the World Bank data base. The employment variable is number of employees.

\section{A.2 Model-Based Diagnostics Section}

In our model diagnostics section, there are five key sets of variables: real state NDP per capita (total and at the sector level), sector-level labor, real personal consumption, relative price of agriculture-to-manufacturing, and manufacturing capital stock. The real state NDP per capita variables are from the EPW, and are constructed in the same manner as the data underlying Figures 1 and 2.

The employment data is from the Census of India. Agricultural labor is defined as the sum of "cultivators" and "agricultural laborers". Manufacturing labor is defined as the sum of "household industry" workers and "manufacturing other than household industry" workers. Lastly, service labor is defined as the sum of "trade and commerce" workers, "transport, storage, and communications" workers, and "other services" workers. These data are linearly interpolated for the non-Census years.

Real personal consumption is constructed as follows. Nominal per capita consumption expenditure is from the World Bank data base variable "overall mean per capital monthly 
expenditures by state". There are separate variables for rural and urban areas. An (allIndia) population weighted average of these two variables is used to create the final monthly nominal per capita expenditure series. These series are multiplied by 12 to yield an annual series. Each series is then deflated by the implicit NDP deflator derived from dividing the current price NDP series by the constant price NDP series.

The agriculture-industry terms of trade variable, which we use as a measure of $p_{a} / p_{m}$, is from Deb (2002). This paper compares many indices for the net barter terms of trade for Indian agriculture. We use the series that draws from Thamarajakshi (1994). That series ends in 1991. We augment this series using the rate of growth of the ratio of the implicit price deflators for agriculture and for non-agriculture.

Lastly, the manufacturing capital stock data is from the ASI and Besley and Burgess (2004). We use the fixed capital stock variable. This is deflated by the overall state NDP implicit price deflator, i.e., the same deflator used to deflate the consumption variable. 


\section{References}

[1] Abler, David G., George S. Tolley, and G.K. Kripalani, 1994, Technical Change and Income Distribution in Indian Agriculture. Boulder, CA. Westview Press.

[2] Banerjee, Abhijit, and Kaivan Munshi, 2004, "How Efficiently is Capital Allocated? Evidence from the Knitted Garment Industry in Tirupur." Review of Economic Studies $71,19-42$.

[3] Banerjee, Abhijit, and Esther Duflo, 2004, "Growth Theory through the Lens of Development Economics." manuscript, MIT, forthcoming, Handbook of Economic Growth.

[4] Besley, Timothy, and Robin Burgess, 2004, "Can Labor Regulations Hinder Economic Performance? Evidence from India," Quarterly Journal of Economics 119 (1), 91-134.

[5] Census of India, 1961, 1971, 1981, 1991, Central Statistical Office, India.

[6] Chari, V. V., Patrick J. Kehoe, and Ellen McGrattan, 2004, "Business Cycle Accounting," NBER Working Paper 10351.

[7] Cole, Harold L., and Lee Ohanian, 2002, "The U.S. and U.K. Great Depressions through the Lens of Neoclassical Growth Theory," American Economic Review 92 (2), 28-32.

[8] Cole, Harold L., and Lee Ohanian, 2004, "New Deal Policies and the Persistence of the Great Depression: A General Equilibrium Analysis," Journal of Political Economy 112 (4), 779-816.

[9] Deb, Surajit, 2002. "The Debate on Agriculture-Industry Terms of Trade in India," Working Paper No. 109, Centre for Development Economics, Delhi School of Economics.

[10] Duraismay, P., 2002, "Changes in Returns to Education in India, 1983-94: by Gender, Age-Cohort and Location." Economics of Education Review. 21, 609-22.

[11] Economic and Political Weekly Research Foundation, CD-ROM on "Domestic Product 
of States of India, 1960-61 to 2000-01" and on "National Account Statistics of India, 1950-51 to 2000-01".

[12] Gollin, Douglas, 2002, "Getting Income Shares Right." Journal of Political Economy $110(2), 458-74$.

[13] Hall, Robert, and Charles Jones, 1999, "Why Do Some Countries Produce So Much More Output per Worker than Others?", Quarterly Journal of Economics, 114, 83-116.

[14] Ingram, Beth F., Narayana Kocherlakota, and N. Eugene Savin, 1994, "Explaining Business Cycles: A Multiple Shock Approach." Journal of Monetary Economics 34, $415-428$.

[15] Kehoe, Timothy, and Kim Ruhl, 2003, "Recent Great Depressions: Aggregate Growth in New Zealand and Switzerland", manuscript, University of Minnesota and Federal Reserve Bank of Minneapolis.

[16] Klenow, Peter, and Andres Rodriguez-Clare, 1997, "The Neoclassical Revival in Growth Economics: Has it Gone Too Far?", in Ben Bernanke and Julio Rotemberg, eds., NBER Macro Annual 1997 (Cambridge, MA: MIT press).

[17] Mulligan, Casey B., 2002, "A Dual Method of Empirically Evaluating Dynamic Competitive Equilibrium Models with Market Distortions, Applied to the Great Depression and World War II." NBER Working Paper 8775.

[18] Ozler, Berk, Gaurav Datt and Martin Ravallion, 1996, "A Database on Poverty and Growth in India". World Bank.

[19] Psacharopoulos, George, 1994, "Returns to Investment in Education: A Global Update." World Development 22, 1325-43.

[20] Thamarajakshi, R., 1994, Intersectoral Relationships in a Developing Economy, Academic Foundation, Delhi, India. 
Table 1: Output per Worker and Decomposition

\begin{tabular}{rr|rrr}
\multicolumn{5}{c}{ Maharashtra } \\
& $\mathrm{Y} / \mathrm{L}$ & $(\mathrm{K} / \mathrm{Y})^{\wedge} 0.5$ & $\mathrm{H} / \mathrm{L}$ & $\mathrm{A}$ \\
\cline { 2 - 5 } 1961 & 11453 & 1.44 & 1.27 & 6278 \\
1971 & 15731 & 1.68 & 1.38 & 6777 \\
1981 & 18305 & 1.86 & 1.50 & 6587 \\
1991 & 25759 & 1.71 & 1.64 & 9157
\end{tabular}

\begin{tabular}{rr|rrr}
\multicolumn{4}{c}{ West Bengal } \\
& $\mathrm{Y} / \mathrm{L}$ & $(\mathrm{K} / \mathrm{Y})^{\wedge} 0.5$ & $\mathrm{H} / \mathrm{L}$ & $\mathrm{A}$ \\
\cline { 2 - 5 } 1961.00 & 13783 & 1.53 & 1.36 & 6625 \\
1971.00 & 16021 & 1.74 & 1.41 & 6527 \\
1981.00 & 17481 & 1.91 & 1.48 & 6154 \\
1991.00 & 19743 & 1.67 & 1.60 & 7385
\end{tabular}

Note: $\mathrm{Y} / \mathrm{L}$ is expressed in rupees/worker in 1993-94 prices

Table 2: Sources of Differences in Growth Between West Bengal and Maharashtra

West Bengal relative to Maharasthra (normalized so $1961=1$ )

\begin{tabular}{ll|rrl} 
& $Y / L$ & $(K / Y)^{\wedge} 0.5$ & $H / L$ & $A$ \\
\cline { 2 - 5 } 1961 & 1.000 & 1.000 & 1.000 & 1.000 \\
1971 & 0.846 & 0.976 & 0.950 & 0.913 \\
1981 & 0.794 & 0.973 & 0.921 & 0.885 \\
1991 & 0.637 & 0.922 & 0.903 & 0.764
\end{tabular}

